\title{
OGT (O-GlcNAc Transferase) Selectively Modifies Multiple Residues Unique to Lamin A
}

\author{
Dan N. Simon ${ }^{1,+, \ddagger}$, Amanda Wriston ${ }^{2,+}$, Qiong Fan ${ }^{3,+}{ }^{\mathbb{D}}$, Jeffrey Shabanowitz ${ }^{2}$, \\ Alyssa Florwick ${ }^{1, \S}$, Tejas Dharmaraj ${ }^{1}$, Sherket B. Peterson ${ }^{4} \|$, Yosef Gruenbaum ${ }^{5}$, \\ Cathrine R. Carlson ${ }^{6}$, Line M. Grønning-Wang ${ }^{3}$, Donald F. Hunt ${ }^{2,7}$ and Katherine L. Wilson ${ }^{1, *}$ \\ 1 Department of Cell Biology, Johns Hopkins University School of Medicine, 725 North Wolfe Street, \\ Baltimore, MD 21205, USA; dsimon01@rockefeller.edu (D.N.S.); alyssa.florwick@duke.edu (A.F.); \\ tdharma1@jhu.edu (T.D.) \\ 2 Department of Chemistry, University of Virginia, Charlottesville, VA 22904, USA; \\ asw5kg@virginia.edu (A.W.); js4c@virginia.edu (J.S.); dfh@virginia.edu (D.F.H.) \\ 3 Department of Nutrition, Institute of Basic Medical Sciences, University of Oslo, 0317 Oslo, Norway; \\ qiong.fan@medisin.uio.no (Q.F.); lmgronningwang@gmail.com (L.M.G.-W.) \\ 4 Department of Biological Chemistry, Johns Hopkins University School of Medicine, \\ Baltimore, MD 21205, USA; speter54@its.jnj.com \\ 5 Department of Genetics, Institute of Life Sciences, Hebrew University of Jerusalem, \\ Givat Ram Jerusalem 91904, Israel; gru@mail.huji.ac.il \\ 6 Institute for Experimental Medical Research, Oslo University Hospital and University of Oslo, \\ 0450 Oslo, Norway; c.r.carlson@medisin.uio.no \\ 7 Department of Pathology, University of Virginia, Charlottesville, VA 22904, USA \\ * Correspondence: klwilson@jhmi.edu; Tel.: +410-955-1801; Fax: +410-502-7826 \\ + These authors contributed equally to this work. \\ $\ddagger$ Current address: The Laboratory of Cellular and Structural Biology, The Rockefeller University, \\ New York, NY 10065, USA. \\ $\S$ Current address: Department of Biochemistry, Duke University School of Medicine, Durham, NC 27708, USA. \\ || Current address: Global Oral Care R\&D, Johnson \& Johnson, Skillman, NJ 08558, USA.
}

Received: 16 April 2018; Accepted: 14 May 2018; Published: 17 May 2018

check for updates

\begin{abstract}
The LMNA gene encodes lamins A and $\mathrm{C}$ with key roles in nuclear structure, signaling, gene regulation, and genome integrity. Mutations in LMNA cause over 12 diseases ('laminopathies'). Lamins A and C are identical for their first 566 residues. However, they form separate filaments in vivo, with apparently distinct roles. We report that lamin $\mathrm{A}$ is $\beta$-O-linked $\mathrm{N}$-acetylglucosamine-(O-GlcNAc)-modified in human hepatoma (Huh7) cells and in mouse liver. In vitro assays with purified $O-G l c N A c$ transferase (OGT) enzyme showed robust O-GlcNAcylation of recombinant mature lamin A tails (residues 385-646), with no detectable modification of lamin B1, lamin $C$, or 'progerin' $(\Delta 50)$ tails. Using mass spectrometry, we identified $11 O$-GlcNAc sites in a 'sweet spot' unique to lamin A, with up to seven sugars per peptide. Most sites were unpredicted by current algorithms. Double-mutant (S612A/T643A) lamin A tails were still robustly O-GlcNAc-modified at seven sites. By contrast, O-GlcNAcylation was undetectable on tails bearing deletion $\Delta 50$, which causes Hutchinson-Gilford progeria syndrome, and greatly reduced by deletion $\Delta 35$. We conclude that residues deleted in progeria are required for substrate recognition and/or modification by OGT in vitro. Interestingly, deletion $\Delta 35$, which does not remove the majority of identified O-GlcNAc sites, does remove potential OGT-association motifs (lamin A residues 622-625 and 639-645) homologous to that in mouse Tet1. These biochemical results are significant because they identify a novel molecular pathway that may profoundly influence lamin A function. The hypothesis that lamin A is selectively regulated by OGT warrants future testing in vivo, along with two predictions: genetic variants may contribute to disease by perturbing OGT-dependent regulation, and nutrient or other stresses might cause OGT to misregulate wildtype lamin A.
\end{abstract}


Keywords: lamin; nuclear lamina; O-GlcNAcylation; $\mathrm{O}$-linked $\mathrm{N}$-acetylglucosamine (O-GlcNAc) Transferase (OGT)

\section{Introduction}

Lamins, encoded by three human genes ( $L M N A, L M N B 1$, and $L M N B 2)$, form nuclear intermediate filaments that support nuclear structure, cell mechanics, development, genome organization, DNA repair, signaling, and tissue-specific gene silencing [1-3]. Lamins have a conserved molecular structure; each polypeptide has a small globular 'head' domain, a long coiled-coil 'rod' domain, and a 'tail' comprising an Ig-fold domain as well as, in the case of lamin A, an extended unstructured region [4-6]. Mutations in LMNA cause diverse tissue-specific diseases [7]. Some 'laminopathies' affect mainly striated muscle (e.g., Emery-Dreifuss muscular dystrophy; dilated cardiomyopathy), whereas others perturb metabolism, causing insulin resistance syndrome [8] or Dunnigan-type familial partial lipodystrophy (FPLD2). FPLD2 is a puberty-onset disorder characterized by lipodystrophy, muscle hypertrophy, insulin-resistant diabetes [9,10], and elevated (dysregulated) hepatic glucose production [11]. LMNA missense mutations are also reported in patients with metabolic syndrome [12,13], although genetic causality has not been established. In rare cases, LMNA mutations cause Hutchinson-Gilford progeria syndrome (HGPS) or related phenotypes [14]. Most HGPS patients have a mutation that alters pre-mRNA splicing, generating a 50-residue deletion (' $\triangle 50$ ') lacking the site required for ZMPSTE24-dependent proteolytic maturation of the lamin A precursor $[15,16]$. The resulting permanently farnesylated protein, named 'progerin', has acute and long-term effects on nuclear structure and function [3,17]. About $35 \%$ of progerin-expressing HGPS patients are also insulin-resistant [18].

These metabolic phenotypes drew our attention to evidence that lamin A is modified by a nutrient, stress-responsive enzyme named OGT (O-GlcNAc transferase), which adds a simple sugar, $\mathrm{O}$-GlcNAc ( $\beta$-O-linked $\mathrm{N}$-acetylglucosamine), to Serine or Threonine residues of target proteins. Endogenous lamin A is O-GlcNAc modified at two sites (S612 and T643) in mitotic HeLa cells [19]. $O$-GlcNAc is a ubiquitous, reversible, and dynamic modification that controls translation, transcription, signal transduction, mitosis, and many other cellular pathways [20]. O-GlcNAc is added to target proteins by OGT and removed by O-GlcNAcase (OGA), each encoded by a single essential gene in mammals [21-23]. Notably, OGT is 'tuned' to metabolism in liver, kidney, and pancreatic $\beta$-cells; its catalytic activity increases in tandem with cellular levels of glucose or glucosamine, which are converted via the hexosamine biosynthetic pathway to UDP-GlcNAc, the donor substrate for $O$-GlcNAcylation reactions [24-26]. OGT activity can protectively increase during stress, including recovery of the heart from ischemic injury [27]. However, long-term cardiomyopathy associated with diabetes, aging, and hypertension all correlate with aberrantly high levels of protein O-GlcNAcylation, suggesting that OGT hyper-activity perturbs heart function [28]. Protein hyper-O-GlcNAcylation has pathophysiological implications in insulin resistance, non-alcohol fatty liver disease, and fibrosis, and is also characteristic of diabetic nephropathy [29], the leading cause of chronic kidney disease and a significant long-term complication of diabetes.

We investigated potential O-GlcNAc modification of A-type lamins in hepatoma (Huh7) cells and liver tissue. We also tested recombinant purified tail domains of A- and B-type lamins as potential substrates for OGT in vitro. We report extensive O-GlcNAc modification of residues unique to lamin A in vitro, and evidence that lamin A substrate recognition or modification by OGT requires residues deleted in progeria.

\section{Materials and Methods}

\subsection{Cell Culture}

Huh7 liver hepatoma cells grown at passages $15-30$ were maintained in high glucose ( $25 \mathrm{mM})$ DMEM (D6546; Sigma-Aldrich, St. Louis, MO, USA) supplemented with 10\% FBS, 4 mM L-glutamine, 
and $1 \%$ penicillin-streptomycin. Subconfluent cells in $10 \mathrm{~cm}$ culture dishes were adapted to physiological glucose (5 mM) DMEM (D6046; Sigma-Aldrich) overnight before culturing cells in physiological glucose or high glucose for $24 \mathrm{~h}$.

\subsection{Nuclear Extraction, Immunoprecipitation, and Western Blotting}

Nuclear lysates from Huh7 cells were prepared using the NE-PER extraction kit (Pierce Biotechnology, Waltham, MA, USA) with the following inhibitors added: $1 \mathrm{mM} \mathrm{NaF}, 1 \mathrm{mM} \mathrm{Na} \mathrm{VO}_{4}$, $1 \mathrm{mM} \beta$-glycerophosphate, $1 \mu \mathrm{M}$ GlcNAc-thiazoline (OGA inhibitor), and Complete ${ }^{\mathrm{TM}}$ protease inhibitors (Roche Applied Science, Penzberg, Germany), followed by sonication on ice (30 s on, $30 \mathrm{~s}$ off per session; three sessions), and centrifugation $(10 \mathrm{~min}, 16,000 \times \mathrm{g})$. Supernatant (nuclear lysate) proteins were stored at $-20^{\circ} \mathrm{C}$. For each immunoprecipitation, $100 \mu \mathrm{g}$ nuclear lysate proteins were pre-cleared by rotating with Protein A/G agarose (sc-2003; Santa Cruz Biotechnology, Santa Cruz, CA, USA) for $1 \mathrm{~h}\left(4^{\circ} \mathrm{C}\right)$, then centrifuged $(2 \mathrm{~min}, 500 \times \mathrm{g})$. Supernatants were incubated with a mouse monoclonal antibody against human lamin A/C (clone 5G4; kindly provided by Robert Goldman, Northwestern University; $1 \mu \mathrm{g}$ per reaction), rotated overnight $\left(4^{\circ} \mathrm{C}\right)$, and then added to $20 \mu \mathrm{L}$ Dynabeads Protein $\mathrm{G}$ (Invitrogen, Carlsbad, CA, USA) and rotated for $1 \mathrm{~h}\left(4^{\circ} \mathrm{C}\right)$. Immunoprecipitates were washed thrice in Phosphate-buffered saline (PBS) with $0.2 \%$ NP-40 and eluted by boiling for $10 \mathrm{~min}$ in NuPage LDS sample buffer. Nonspecific mouse IgG (Jackson ImmunoResearch Laboratories, West Grove, PA, USA) was used as the negative control.

Proteins ( $8 \%$ input lysate; $50 \%$ immunoprecipitate) were resolved on 10\% SDS-PAGE gels (BioRad, Hercules, CA, USA) and transferred to PVDF membranes (Immobilon-FL, Millipore, Burlington, MA, USA). Blots were blocked and incubated overnight with primary antibodies against $O$-GlcNAc (mouse monoclonal antibody $\mathrm{CTD}_{110.6}$; Covance MMS-248R, diluted 1:5000), OGT (AL25, diluted 1:2000), lamins A/C (5G4, diluted 1:2500), or lamin A (L1293; Sigma-Aldrich; diluted 1:2000). Secondary HRP-conjugated anti-mouse (115-035-174) and anti-rabbit (211-032-171) IgG antibodies (both from Jackson ImmunoResearch Laboratories) were used at 1:10,000 dilution. Secondary anti-mouse IgM antibodies (A8786; Sigma-Aldrich) were used at 1:5000 dilution. Blots were developed using ECL (Pierce Biotechnology) and quantified from five independent experiments using ImageJ software bundled with 64-bit Java 1.6.0_2.0 (NIH, Bethesda, MD, USA).

\subsection{Succinylated Wheat Germ Agglutinin (sWGA) Pulldown}

Mouse liver nuclear lysates $\left(100 \mu \mathrm{g}\right.$ per sample) were incubated for $1 \mathrm{~h}\left(4{ }^{\circ} \mathrm{C}\right)$ with protein $\mathrm{A} / \mathrm{G}$ agarose beads (sc-2003; Santa Cruz Biotechnology), then centrifuged. The resulting supernatants (cleared extracts) were transferred to new tubes and incubated overnight (rotating; $4{ }^{\circ} \mathrm{C}$ ) with $40 \mu \mathrm{L}$ succinylated wheat germ agglutinin (sWGA)-agarose (Vector Laboratories, Burlingame, CA, USA). After washing four times with PBS containing $0.2 \%$ NP-40, proteins were eluted from the beads by boiling for $10 \mathrm{~min}$ in NuPage LDS sample buffer, and resolved by SDS-PAGE. The captured proteins were analyzed by immunoblotting as described above.

\subsection{Mice}

Male mice (mixed genetic background based on C57BL/6J and 129/Sv strains, backcrossed with C57BL/6J for at least six generations) were housed in a temperature-controlled $\left(22^{\circ} \mathrm{C}\right)$ facility with a strict $12 \mathrm{~h}$ light/dark cycle. Mice had free access to food and water at all times. STZ (S0130; Sigma-Aldrich) was prepared in a sodium citrate buffer $(50 \mathrm{mmol} / \mathrm{L}, \mathrm{pH} 4.5)$ immediately before injections. STZ-treated mice were treated with two intraperitoneal injections of STZ (100 mg/kg) with a 1-day interval. Seven days after the first STZ injection, mice were included in a fasting-re-feeding experiment. Mice were either fasted for $24 \mathrm{~h}$, or fasted for $24 \mathrm{~h}$ and re-fed for $12 \mathrm{~h}$ on a diet containing $64 \%$ carbohydrates, $31.5 \%$ protein, $4.5 \%$ fat, and no cholesterol (SDS RM no. 1 maintenance, Special Diets Services, Witham, UK). The mice were euthanized by cervical dislocation at 8:00 a.m. and liver 
tissues were snap-frozen in liquid nitrogen and stored at $-80{ }^{\circ} \mathrm{C}$ until further analysis. All use of animals was approved and registered by the Norwegian Animal Research authority.

\subsection{Peptide Arrays and Antibody Epitope Mapping}

To generate peptide arrays, human lamin A (P02545, full length), human lamin C (NP_005563, full length), mouse lamin A (P48678, 588-end), and rat lamin A (P48679, 588-end) were synthesized as 20 mer peptides with three amino acid offsets on cellulose membranes using a Multipep automated peptide synthesizer (INTAVIS Bioanalytical Instruments AG, Koeln, Germany) as described [30]. Peptide array membranes were blocked for $2 \mathrm{~h}$ in $1 \%$ casein in TBST (Tris-buffered saline with $1 \%$ tween) at $22-25{ }^{\circ} \mathrm{C}$, and then incubated overnight at $4{ }^{\circ} \mathrm{C}$ with a primary antibody (5G4 at 1:2500 dilution; L1283 at 1:2000) in TBST/1\% casein. Membranes were then washed three times in TBST (10 $\mathrm{min}$ each) and incubated with affinity-purified horseradish-peroxidase-conjugated polyclonal anti-mouse IgG HRP (NA931V) or anti-rabbit IgG HRP (NA934V), both from GE HealthCare (Little Chalfont, UK). Blots were developed using ECL Prime (RPN 2232, GE HealthCare) and chemiluminescence signals were detected using Las 1000 (Fujifilm, Tokyo, Japan). Lasergene software (DNAStar, Madison, WI, USA) was used to generate peptide sequence alignments.

\subsection{Purification of Recombinant Lamin Tails}

Recombinant His-and-T7-tagged lamin tail polypeptides were expressed in E. coli BL-21, purified using nickel NTA-agarose and stored in a buffer $\left(50 \mathrm{mM} \mathrm{NaHPO}_{4} \mathrm{pH} 8.0,300 \mathrm{mM} \mathrm{NaCl}, 100 \mathrm{mM}\right.$ imidazole, $0.5 \mathrm{mM}$ PMSF) at $-80^{\circ} \mathrm{C}$ until use, as described [31].

\subsection{In Vitro O-GlcNAcylation Reactions}

Each reaction contained $1 \mu \mathrm{g}$ recombinant lamin tails, 1 Unit calf intestinal phosphatase (CIP) (New England Biolabs, Ipswich, MA, USA) and $10 \mathrm{mM}$ UDP-GlcNAc (Sigma-Aldrich), plus or minus $1 \mu \mathrm{g}$ purified recombinant active His-tagged OGT enzyme in a final reaction volume of $20 \mu \mathrm{L}$ in $50 \mathrm{mM}$ Tris- $\mathrm{HCl} \mathrm{pH} \mathrm{7.4.} \mathrm{Recombinant} \mathrm{OGT} \mathrm{was} \mathrm{purified} \mathrm{as} \mathrm{described} \mathrm{[32].} \mathrm{Reactions} \mathrm{were} \mathrm{incubated} \mathrm{for} 2 \mathrm{~h}$ at $22-25{ }^{\circ} \mathrm{C}$, and then overnight at $4{ }^{\circ} \mathrm{C}$. Reactions were stopped by adding $4 \mathrm{X}$ SDS sample buffer and $33 \%$ of each reaction was resolved on $4-12 \%$ Bis-Tris NuPage gels (Invitrogen), and then transferred to nitrocellulose membranes, blocked for $1 \mathrm{~h}$ at $22-25{ }^{\circ} \mathrm{C}$ with $3 \%$ BSA in PBS, and incubated overnight at $4{ }^{\circ} \mathrm{C}$ with affinity-purified $O$-GlcNAc-specific mouse antibody $\mathrm{CTD}_{110.6}$ (diluted 1:1000), or with a mixture of $\mathrm{CTD}_{110.6}$ antibody and competing (free) GlcNAc sugar $(100 \mathrm{mM})$. Secondary antibodies were horseradish peroxidase-coupled anti-mouse IgM (Santa Cruz SC-2064; diluted 1:10,000) and anti-T7-tag (69048-3; diluted 1:100,000, Novagen, Darmstadt, Germany).

\subsection{Mass Spectrometry}

Recombinant purified His-tagged lamin A tails (wildtype, S612A/T643A, $\Delta 35$ ), O-GlcNAcylated in vitro as described above, were reduced for $1 \mathrm{~h}$ with dithiothreitol (DTT, Sigma-Aldrich) at a molar ratio of 20:1 (DTT/cysteine), carbamidomethylated for $1 \mathrm{~h}$ in the dark with iodoacetamide (IAA, Sigma-Aldrich) at a molar ratio of 3:1 (IAA/DTT), and then proteolytically digested in $100 \mathrm{mM}$ ammonium bicarbonate at a molar ratio of 1:20 (enzyme/substrate) by AspN (Roche Applied Science), quenched with glacial acetic acid (to $\mathrm{pH} 3-4$ ), and stored at $-35^{\circ} \mathrm{C}$. An additional chymotrypsin (Roche Applied Science) digest was performed using similar conditions. For mass spectrometric analysis, a fraction of the digest was pressure loaded onto a precolumn $(360 \mu \mathrm{m}$ o.d. $\times 75 \mu \mathrm{m}$ i.d., fused silica capillary) packed with 6-8 cm of C18 reverse-phase resin (5-20 $\mu \mathrm{m}$ irregular diameter, 120 Á pore size, $\mathrm{YMC}$ ). After a desalting rinse with $0.1 \mathrm{M}$ acetic acid, the precolumn was connected via polytetrafluoroethylene tubing (0.06 in. o.d. $\times 0.012$ in. o.d., Zeus Industrial Products, Branchburg, NJ, USA) to the end of an analytical column $(360 \mu \mathrm{m}$ o.d. $\times 50 \mu \mathrm{m}$ i.d. fused silica capillary) packed $6-8 \mathrm{~cm}$ with C18 reverse-phase resin (5 $\mu \mathrm{m}$ diameter, $120 \AA$ A pore size, YMC) and 
equipped with an electrospray emitter tip [33]. Peptides were gradient eluted directly into the mass spectrometer with an Agilent 1100 series binary LC pump at a flow rate of $\sim 60 \mathrm{~nL} / \mathrm{min}$ with the following gradient: $0-60 \%$ B in $60 \mathrm{~min}, 60-100 \% \mathrm{~B}$ in $65 \mathrm{~min}$, hold at $100 \%$ B for $70 \mathrm{~min}$ (solvent A: $0.1 \mathrm{M}$ acetic acid, solvent B: $70 \%$ acetonitrile). Mass spectra were acquired with a modified front-end electron transfer-enabled [34] high-resolution LTQ-FT or an LTQ-Orbitrap mass spectrometer (Thermo Scientific, Waltham, MA, USA). Mass analyses were completed with one high resolution MS1 (60,000 at $m / z 400)$ scan followed by six collisionally activated dissociation (CAD) and electron transfer dissociation (ETD) MS2 scans, acquired with the LTQ operating in either data-dependent or targeting mode. Azulene was used for ETD reactions with times of 30-50 ms.

Data from MS/MS analyses were searched against human lamin A using the Open Mass Spectrometry Search Algorithm (OMSSA; [35]). OMSSA search tolerances were $\pm 0.01 \mathrm{Da}$ and $\pm 0.35 \mathrm{Da}$ for precursor and product ion masses, respectively. For ETD spectra, search parameters were set to exclude reduced charge species from peak lists prior to searching. Database searches were completed using either AspN or no enzyme specifications and allowing up to three missed cleavages. Specified variable modifications: carbamidomethylation of Cys, oxidation of Met, and O-GlcNAcylation of Ser and Thr. While OMSSA searches were used as a guide, all spectra and O-GlcNAc site modifications were validated by manual interpretation of the raw data.

\section{Results}

\subsection{Native Lamin A is O-GlcNAcylated in Human Hepatoma Cells and Mouse Liver}

To assess potential O-GlcNAcylation of A-type lamins, we cultured human hepatoma (Huh7) cells for $24 \mathrm{~h}$ in medium containing physiological $(5 \mathrm{mM})$ or high $(25 \mathrm{mM})$ glucose. A-type lamins were immunoprecipitated from sonicated Huh7 nuclear lysates using monoclonal antibody 5G4, which recognizes the Ig-fold domain (residues 466-484; Supplemental Figure 1A) in both lamin A and lamin C. Immunoprecipitates (50\% per lane) were resolved by SDS-PAGE with input lysate controls (8\%), and immunoblotted (Figure 1A). One set of samples was probed using antibody $\mathrm{CTD}_{110.6 \text {, }}$ which recognizes the $\mathrm{O}-\mathrm{GlcNAc}$ modification, and then stripped and re-probed for lamins A/C using antibody 5G4 (Figure 1A). The $\sim 73 \mathrm{kD}$ lamin A band was consistently O-GlcNAc-positive in both concentrations of glucose (asterisk; Figure $1 \mathrm{~A} ; n=5$ ), demonstrating $O$-GlcNAc modification of lamin A in cultured human hepatoma cells. However, the level of lamin A O-GlcNAcylation in 5-vs. 25-mM glucose, and the extent to which other O-GlcNAcylated proteins co-immunoprecipitated with lamin A in $25 \mathrm{mM}$ glucose, varied between experiments and was not studied further. O-GlcNAc signals were not detected on lamin C ( $\sim 60 \mathrm{kD}$; Figure 1A). These results demonstrated O-GlcNAcylation of endogenous lamin A in proliferating hepatoma cells, consistent with previous results from mitotic HeLa cells [19].

To determine whether lamin A was $O$-GlcNAcylated in a non-proliferating tissue, we analyzed liver lysates from wildtype mice that were either fasted for $24 \mathrm{~h}$, or fasted for $24 \mathrm{~h}$ and then re-fed for $12 \mathrm{~h}$ on a regular chow diet to boost overall protein O-GlcNAcylation (see Methods).

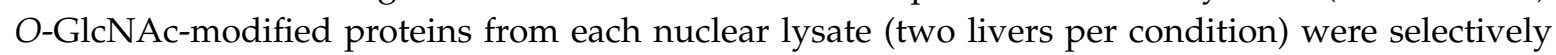
affinity-purified using succinylated Wheat Germ Agglutinin (sWGA; does not bind sialylated proteins). The resulting O-GlcNAc-modified proteins were then resolved by SDS-PAGE and western blotted for O-GlcNAc (antibody CTD 110.6 ) and lamin A (antibody L1293; Figure 1B). Control input lysates were analyzed in parallel. Lysates contained similar levels of input mature lamin A ( 73 kD; Figure 1B, Input). As expected, re-feeding caused an overall increase in O-GlcNAcylation of nuclear proteins $\left(\mathrm{CTD}_{110.6} \mathrm{Ab}\right.$; Figure $\left.1 \mathrm{~B}\right)$. Probing for specific proteins in the affinity-purified samples revealed enrichment for two lamin A-specific bands: the expected $\sim 73 \mathrm{kD}$ mature lamin A band and a slower-migrating ( 74 kD) band (sWGA; Figure 1B). Pull-downs from mouse liver nuclear lysates, using either WGA (QF \& LMGW, unpublished observations) or sWGA (Figure 1B), all revealed two lamin A bands. The single lamin A band detected in inputs (Figure 1B) corresponded to the faster-migrating band in sWGA (Figure 1B). We speculate that the second band represents 
differentially-modified forms of lamin A that were enriched by sWGA pull-down. Supporting this possibility, two lamin A bands were also detected in mouse liver after enrichment via immunoprecipitation with lamin A/C antibodies (TD \& KLW, unpublished observations).

A

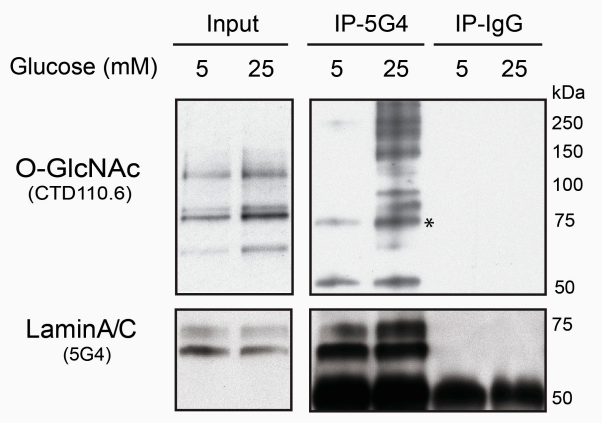

B

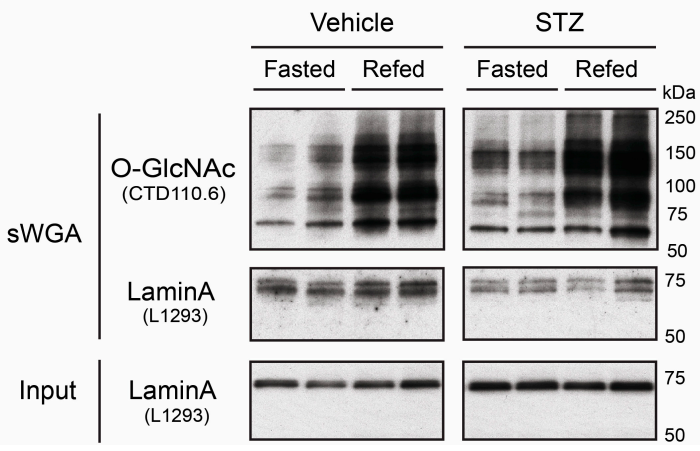

Figure 1. O-GlcNAcylation of native lamin A in human hepatoma (Huh7) cells and mouse liver. (A) Western blots of proteins from human hepatoma (Huh7) cells, cultured for $24 \mathrm{~h}$ in physiological $(5 \mathrm{mM})$ or high $(25 \mathrm{mM})$ glucose, probed with antibody $\mathrm{CTD}_{110.6}$ specific for the $\beta$-O-linked $\mathrm{N}$-acetylglucosamine modification (O-GlcNAc), and then stripped and re-probed with antibody 5G4, specific for lamins A and C (Lamin A/C). Control input lysates, and proteins immunoprecipitated using lamin $\mathrm{A} / \mathrm{C}$ antibody $5 \mathrm{G} 4$ or nonspecific IgG as the negative control, were resolved in parallel gels. Asterisk indicates the $O$-GlcNAc signal corresponding to immunoprecipitated lamin A; (B) Western blots of mouse liver nuclear proteins, before (Input) or after affinity purification on succinylated Wheat Germ Agglutinin (sWGA), which binds O-GlcNAc-modified proteins. We analyzed two livers for each condition. Male mice were either fasted (Fasted), or fasted and then re-fed for $12 \mathrm{~h}$ ('Refed'), and were either pretreated with streptozotocin to induce hyperglycemia ('STZ'), or not ('Vehicle'). Input controls were probed with lamin A-specific antibody L1293. Affinity-purified samples were probed first for the O-GlcNAc modification (antibody $\mathrm{CTD}_{110.6}$ ), and then stripped and re-probed for lamin A (antibody L1293). Control input lysates, and proteins immunoprecipitated using lamin A/C antibody 5G4 or nonspecific IgG as the negative control, were resolved in parallel gels. STZ—-streptozocin.

We found similar sWGA-purification results in liver lysates from mice treated with streptozocin (STZ), which kills pancreatic $\beta$-cells and models diabetes [36]: two lamin A bands, one or both of which were presumably O-GlcNAc-modified (STZ; Figure 1B). The relative abundance of the two lamin A bands could not be interpreted, because the core epitope recognized by antibody L1293 (residues 604-611; Supplemental Figure 1) adjoins a potential O-GlcNAc site (S612; [19]) and potential phosphorylation sites $[37,38]$, and may be differentially accessible on native lamin A. Collectively, these results from hepatoma cells and mouse livers support the hypothesis that lamin A is O-GlcNAc-modified, and hence O-GlcNAc-regulated, in the liver. To explore whether OGT targets lamin A selectively, we compared the tail domains of A- and B-type lamins as biochemical substrates for OGT in vitro. 


\subsection{In Vitro O-GlcNAcylation of Recombinant Lamin Tails}

To identify O-GlcNAc sites, we incubated recombinant lamin tail domains with purified OGT in vitro. We tested nine different tail constructs: lamin B1, lamin $C$, mature lamin A residues 385-646 (wildtype, S612A, T643A, or S612A/T643A), and prelamin A residues 385-664 bearing the progeria-associated $\Delta 35, \Delta 50$, or $\Delta 90$ deletions (Figure $2 \mathrm{~A}$ ). Each purified recombinant T7-tagged lamin tail polypeptide ( $1 \mu \mathrm{g}$ protein) was incubated with UDP-GlcNAc and calf intestinal phosphatase (CIP), plus or minus purified recombinant His-tagged OGT enzyme, for $2 \mathrm{~h}$ at $22-24^{\circ} \mathrm{C}$, and then overnight at $4{ }^{\circ} \mathrm{C}$. The reactions were quenched with SDS sample buffer, resolved by SDS-PAGE and immunoblotted first with antibody $\mathrm{CTD}_{110.6}$, specific for the O-GlcNAc moiety, then stripped and re-probed with antibodies against the T7-tag on lamins. These in vitro O-GlcNAcylation assays revealed robust and specific modification of the recombinant mature lamin A tail domain (Figure 2B). $O$-GlcNAcylation of mature lamin A tails mutated at one or both previously reported O-GlcNAc sites (S612A, T643A, S612A/T643A) was similarly robust (Figure 2B), suggesting OGT targeted alternative $O$-GlcNAc sites. The $O$-GlcNAc signals were specific: potential antibody cross-recognition of recombinant proteins was ruled out by probing duplicate membranes with the O-GlcNAc antibody plus $100 \mathrm{mM}$ free sugar (+GlcNAc; Figure 2C). In vitro O-GlcNAcylation was greatly reduced by deletion $\Delta 35$ (loss of residues 622-658) [16]; trace signals were detected only in long exposures (Figure 2B; 'long exp'). There was no detectable O-GlcNAcylation of the HGPS-associated deletion $\Delta 50(\Delta 608-658 ;$ [15]) or deletion $\Delta 90$ (Restrictive Dermopathy-associated loss of residues 567-658; [39]) in vitro (Figure $2 \mathrm{~B}, \mathrm{C} ; n=3$ ). There were also no specific $O-G l c N A c$ signals on lamin $\mathrm{C}$ or lamin $\mathrm{B} 1$ tails (Figure 2B), or on full-length C. elegans lamin ('ce-lamin'; Figure 2D), which has a short 'B-like' tail. Potential O-GlcNAc modification of the head or rod domain of human lamins was not tested. These results did not rule out potential $O$-GlcNAc modifications of lamin C or B-type tails since negative results can be artifacts of recombinant proteins. However, selective O-GlcNAcylation of lamin A tails in vitro was consistent with our results in hepatoma cells (Figure 1A). These results suggested OGT targets the tail domain of lamin A selectively in vitro and is sensitive to progeria-associated deletions.

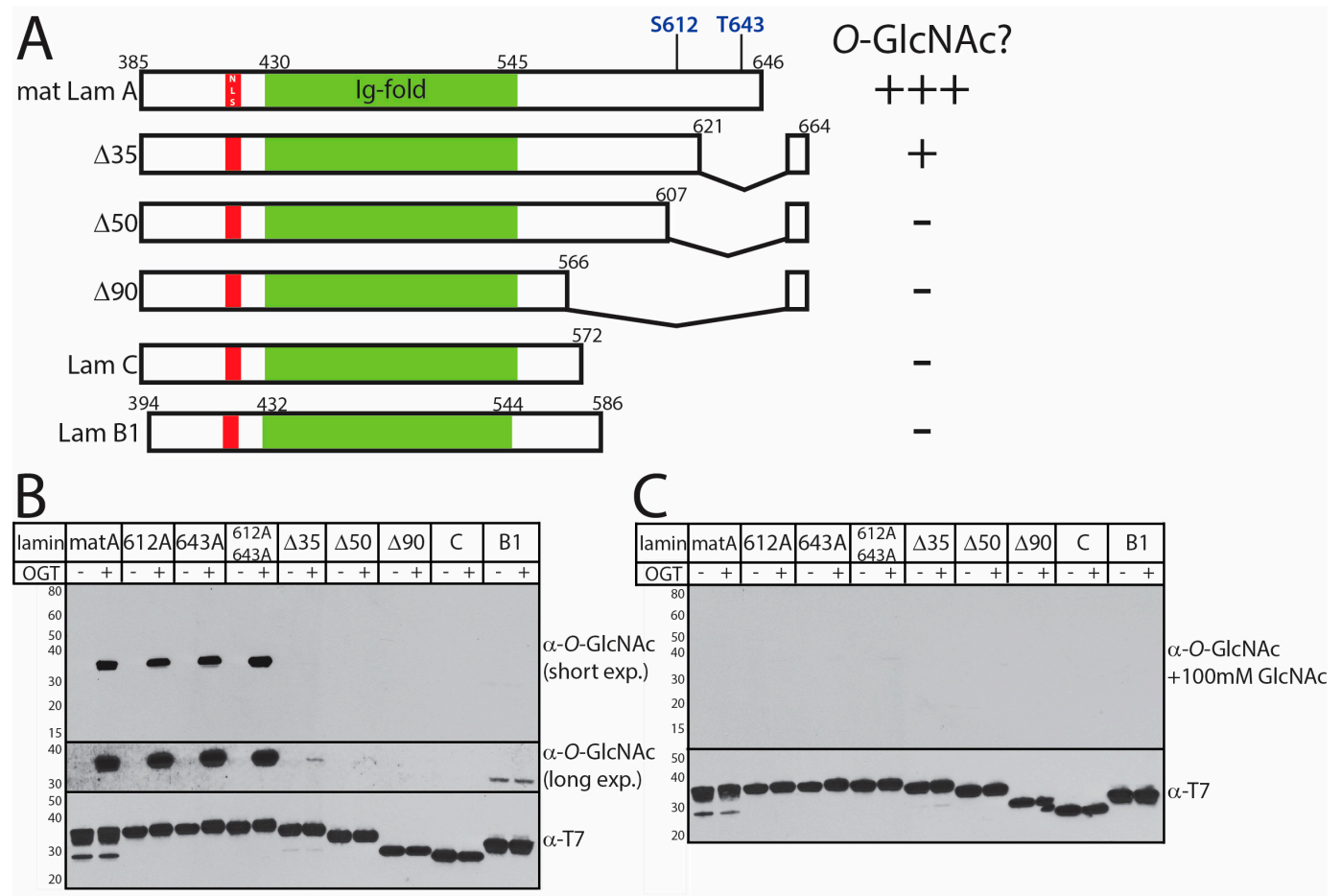

Figure 2. Cont. 


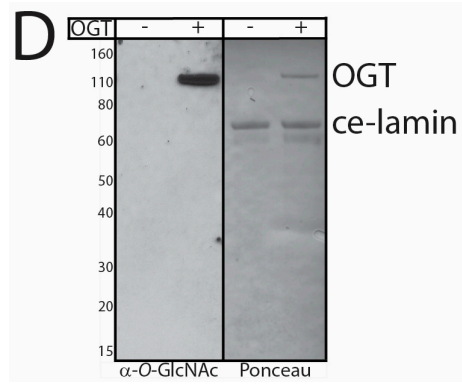

Figure 2. In vitro O-GlcNAcylation of recombinant lamin tails. (A) Schematic diagram of the recombinant lamin tail constructs used as substrates for in vitro modification by recombinant $O$-GlcNAc transferase (OGT) enzyme. These included mature wildtype lamin A tail residues 385-646 ('mat Lam A'); mature lamin A residues 385-646, bearing single or double Ala-substitutions at S612 and T643 [19]; deletions $\Delta 35, \Delta 50$, or $\Delta 90$ in the context of prelamin A tail residues 385-664; and wildtype lamin C ('lam $C^{\prime}$ ) and lamin B1 ('lam B1') tails. The nuclear localization signal (NLS) and Ig-fold domain [40] are indicated. The results for each construct are summarized on the right; $(\mathbf{B}, \mathbf{C})$ in vitro O-GlcNAcylation results, assayed by western blotting with the $\mathrm{CTD}_{110.6} \mathrm{O}$-GlcNAc antibody. Lamin tails (wildtype, S612A, T643A, $\mathrm{S} 612 \mathrm{~A} / \mathrm{T} 643 \mathrm{~A}, \Delta 35, \Delta 50$, or $\Delta 90$; lamin $\mathrm{C}$ or B1) were incubated with UDP-GlcNAc and calf intestinal phosphatase (CIP) with or without OGT for $2 \mathrm{~h}\left(22-25^{\circ} \mathrm{C}\right)$, and then overnight at $4{ }^{\circ} \mathrm{C}$. Reactions were resolved by SDS-PAGE and immunoblotted with antibody $\mathrm{CTD}_{110.6}(\alpha-O-G l c N A c)$ in the absence $(\mathbf{B})$ or presence (C) of competing $100 \mathrm{mM}$ free sugar, and then stripped and re-probed with T7-tag antibodies $(\alpha$-T7-tag) to detect lamin tails; (D) in vitro $O$-GlcNAcylation results for recombinant full-length $C$. elegans lamin ('ce-lamin'), detected by Ponceau-staining prior to immunoblotting for $O$-GlcNAc, were negative. OGT activity was confirmed by auto-O-GlcNAcylation of the OGT band ('OGT’).

\subsection{O-GlcNAc Site Identification by Mass Spectrometry}

$O$-GlcNAc sites were identified by mass spectrometry analysis of three in vitro-modified samples: wildtype mature lamin A tail, S612A/T643A-mutated mature lamin A tail, and pre-lamin A bearing the $\triangle 35$ HGPS-associated deletion. Samples were digested with either AspN alone or AspN followed by chymotrypsin. The generated peptides were analyzed by on-line HPLC-MS/MS on a high-resolution mass spectrometer (see Methods). Peptides were fragmented by both collisionally activated dissociation (CAD) and electron transfer dissociation (ETD) in a data-dependent mode. We achieved nearly $90 \%$ peptide coverage of both the wildtype and S612A/T643A-mutated lamin A tails. Coverage of $\Delta 35$ was lower $(71 \%)$, but included 48 of 57 total Ser/Thr residues in the $\Delta 35$ tail (Figure 3A). The O-GlcNAcylated peptides were identified from CAD spectra by either the O-GlcNAc oxonium signature peak at $m / z 203 \mathrm{amu}$, or they exhibited the charge reduced product ion with the loss of $203 \mathrm{amu}$, as shown in Figure 4A. ETD spectra were used to identify sites modified by O-GlcNAc. We detected a total of 11 unique $O$-GlcNAc sites in the wildtype lamin A tail, four of which were more abundant, based qualitatively on the relative abundance of the ions corresponding to the O-GlcNAc sites: S612, S613, S618, and T643 ('more abundant'; Figure 3B). The seven less abundant sites were S603, S619, T623, and four others (S615, S616, T621, and S628), and were detected only on heavily O-GlcNAc-modified peptides ('less abundant'; Figure 3B). These results validated previously reported sites S612 and T643 [19] and identified nine more O-GlcNAc sites in the mature lamin A tail.

Lamin A tail peptides were frequently modified at multiple sites (up to seven; Figure 3B,C). Mass spectrometry analysis of the AspN peptide containing residues 596-638 from wildtype lamin A revealed that $37.3 \%$ were unmodified, $9 \%$ had one O-GlcNAc, 35.8\% were di-GlcNAcylated, $14 \%$ were tri-GlcNAcylated, and the remaining $3.9 \%$ had four to seven O-GlcNAc modifications (Figure 3B,C). Percentages are based on the chromatographic peak area of each species compared to the chromatographic peak area of all species combined. Only two di-GlcNAcylated pairs were detected: S612 + S613 and S612 + S603. The ETD spectrum of the S612 + S613 di-GlcNAcylated pair, with near complete sequence coverage, is shown in Figure 4B. The most frequent triple combinations 
were S612 + S613 plus one of S616, T623, or S603; together these five sites accounted for all triples in the wildtype tail.

We also identified sites in the corresponding AspN peptide from the double-mutant (S612A/T643A; 'AA') tail to determine how OGT responded to substrates lacking both previously identified O-GlcNAc sites [19]. The mono-GlcNAc species (invariably at S613) predominated (50.1\%) over the unmodified species (24.5\%; Figure 3B). The di- and tri-GlcNAc species were also relatively abundant $(18.7 \%$ and $5 \%)$, and the tetra- and penta-GlcNAc species were present at $<2 \%$ each ('AA'; Figure 3B). Collectively, $>25 \%$ of double-mutant tails had two or more modifications (Figure 3B). Mass spectrometry analysis of the double mutant revealed O-GlcNAc modifications at three predominant sites (S613, S615, and S616) and four less abundant sites (S618, S619, T621, and T623; Figure 3B). We were unable to site-map the mono-O-GlcNAcylated peptide corresponding to residues 639-646 due to poor sequence coverage; however, given the T643A mutation, this peptide had only one potential site, S645, suggesting O-GlcNAc-modification of residue S645 in the double mutant. Modification at $S 645$ was not detected in wildtype or $\Delta 35$ tails. We concluded that the S612A/T643A double-mutant tail remained attractive as a substrate for OGT.

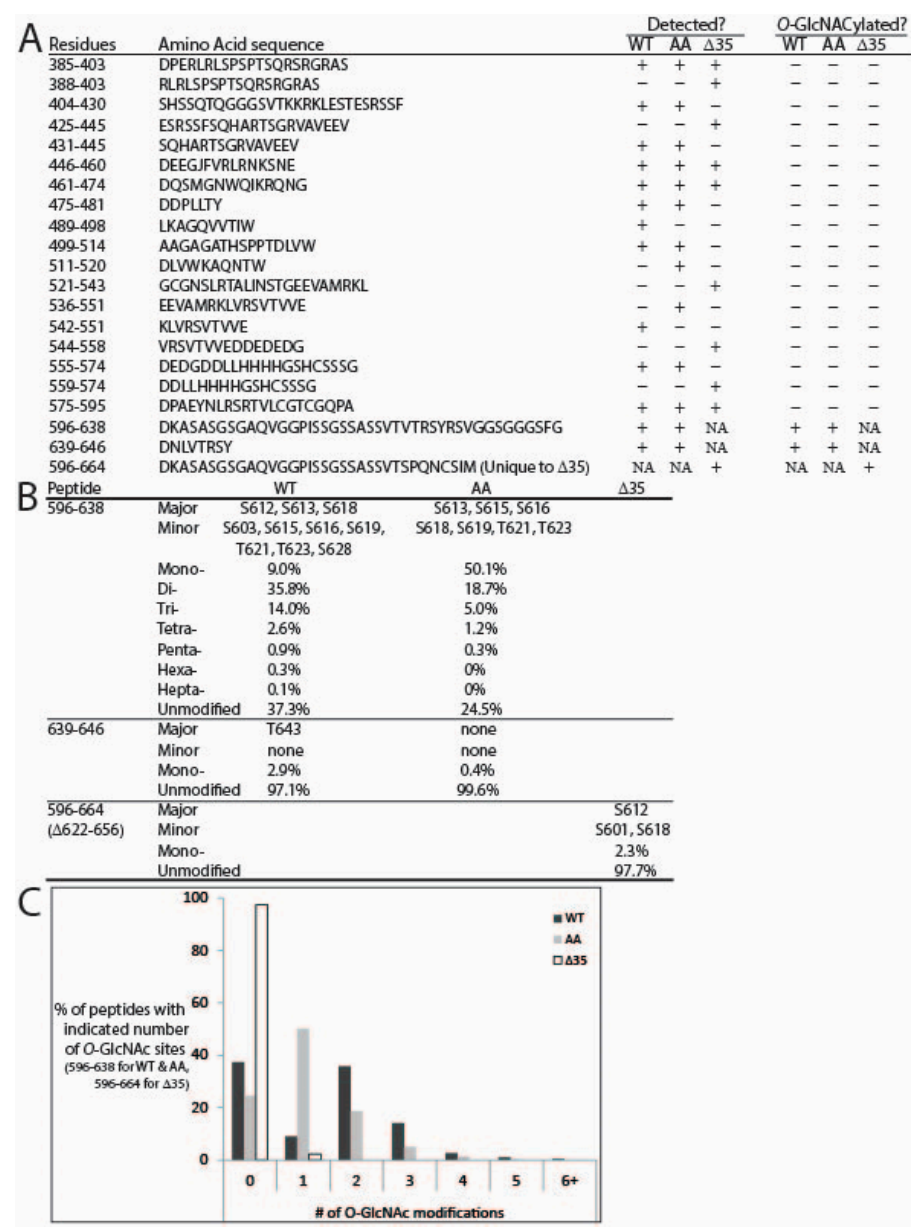

Figure 3. Mass spectrometry identification of $O$-GlcNAc sites in recombinant lamin A tail polypeptides. (A) Combined sequence coverage of AspN and AspN-Chymotrypsin digests of lamin A tails. Note: peptide DNLVTRSY (residues 639-646) included a vector-derived C-terminal residue L647; (B) summary and relative abundances of identified $O$-GlcNAc sites in each indicated peptide from wildtype (WT), double-mutant S612A/T643A (AA), or $\Delta 35$ lamin A tails; (C) for peptides comprising wildtype lamin A residues 596-638, or the corresponding double-mutant (S612A/T643A) peptide 596-638, the percentages of peptides with zero (unmodified), one, two, or more $\mathrm{O}-\mathrm{GlcNAc-modified} \mathrm{sites} \mathrm{are} \mathrm{graphed.}$ 

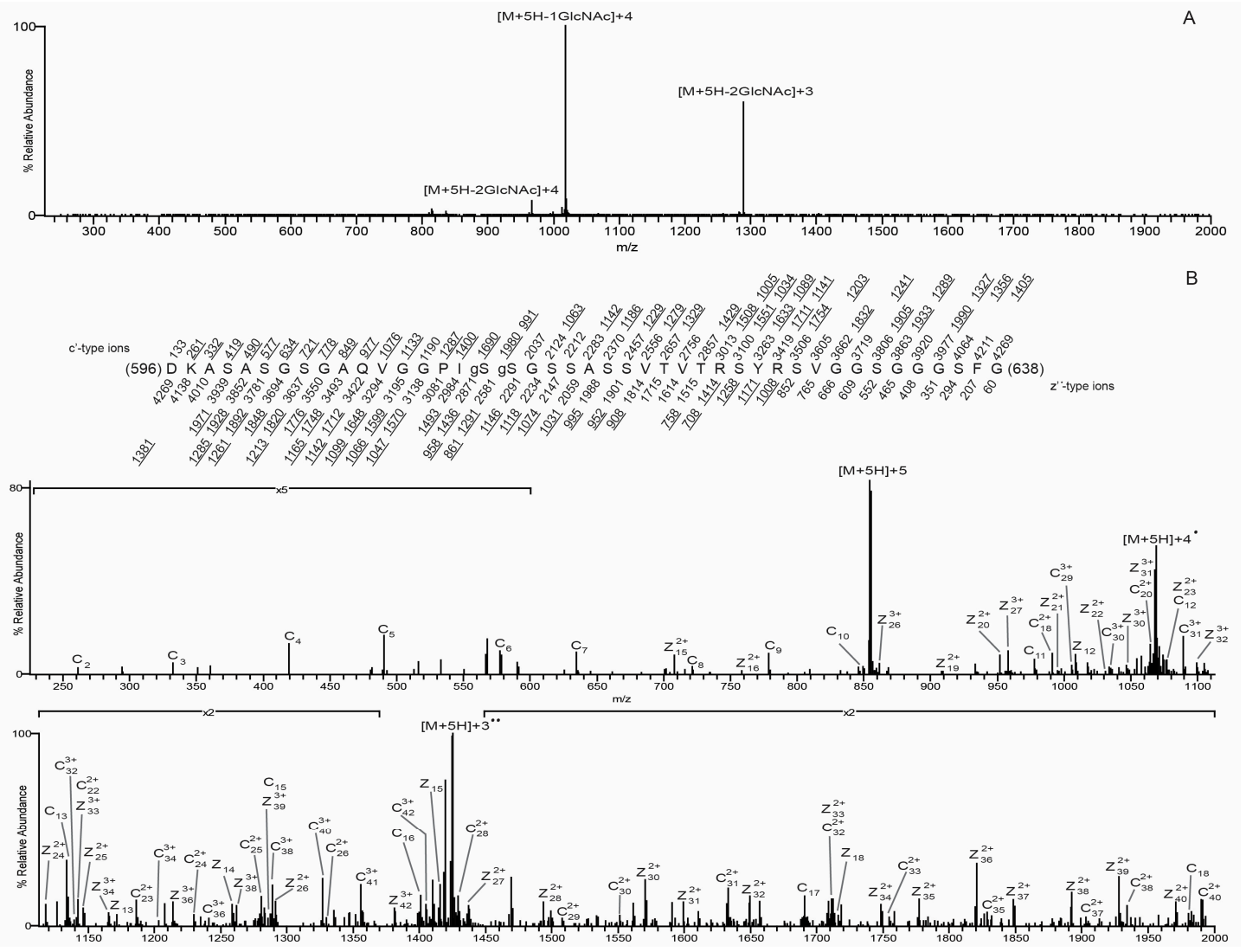

Figure 4. O-GlcNAc site mapping on the wildtype lamin A tail via liquid chromatography-MS/MS. (A) Collisionally activated dissociation (CAD) MS/MS spectrum recorded on the $(\mathrm{M}+5 \mathrm{H})^{5+}$ ions $(m / z$ 855.2046) of the di-GlcNAcylated peptide DKASASGSGAQVGGPIgSgSGSSASSVTVTRSYRSVGGSG GGFG. The CAD spectrum contains the charge-reduced ions minus the loss of $1 \mathrm{GlcNAc}, 203 \mathrm{Da}$, at $\mathrm{m} / z$ 1018 for the +4 species, and the charge-reduced ion minus the loss of 2GlcNAc residues, $406 \mathrm{Da}$, at $m / z 1289$ for the +3 species and 967 for the +4 species; (B) an electron transfer dissociation (ETD) MS/MS spectrum recorded on the $[\mathrm{M}+5 \mathrm{H}]^{5+}$ ions $(\mathrm{m} / \mathrm{z}$ 855.2046) of the di-GlcNAcylated peptide DKASASGSGAQVGGPIgSgSGSSASSVTVTRSYRSVGGSGGGFG. Predicted product ions of types c'- and $\mathrm{z}^{\prime \bullet}$ - are listed above and below the peptide sequence, respectively. Singly charged ions are listed as monoisotopic masses, and doubly and triply charged ions are listed as average masses. ETD product ions are labeled in the ETD spectrum. Observed product ions are underlined and are sufficient to define the $\mathrm{O}$-GlcNAc residues at Ser612 and Ser613, indicated by ' $\mathrm{gS}$ ' in the amino acid sequence.

With the S612A/T643A-mutated substrate, OGT apparently compensated by targeting three predominant sites adjoining residue 612 (S613, S615, and S616) plus nearby residues S618, S619, T621, and T623. However, there were fewer 'multiples': the peptide comprising residues 596-638 was more likely to have one modification ( $50.1 \%$ versus $9 \%$ of wildtype), and less likely to have two $(18.7 \%$ vs. $35.8 \%$ of wildtype), three ( $5 \%$ vs. $14 \%$ of wildtype), or four or more modifications (1.5\% vs. $3.9 \%$ of wildtype; Figure 3B). In the peptide comprising residues 596-626, we detected di-GlcNAcylation at residues S613 + S616 and S613 + S615, as well as tri-GlcNAcylation at $\mathrm{S} 613+\mathrm{S} 616+\mathrm{S} 618$ and S613 + S615 + T621. In a longer version of this peptide (residues 596-638), we detected di-GlcNAcylation mainly on S613 + S615 and less often on S613 + (S616, S618, or S619). Figure $5 \mathrm{~A}$ shows the CAD spectrum of the di-GlcNAcylated species, with the most abundant peaks being the charge-reduced product ion with the loss of 203 and 406, one and two O-GlcNAc moieties, respectively. Figure 5B shows the ETD spectrum of the S613 and S618 di-GlcNacylated peptide with almost full sequence coverage. Tri-GlcNAcylation occurred on S613 plus different combinations of 
S615, S616, T621, and/or T623 as the second and third sites. We speculate that the first O-GlcNAc modification (e.g., S612 in wildtype; S613 in the AA mutant) strongly favors further modification.
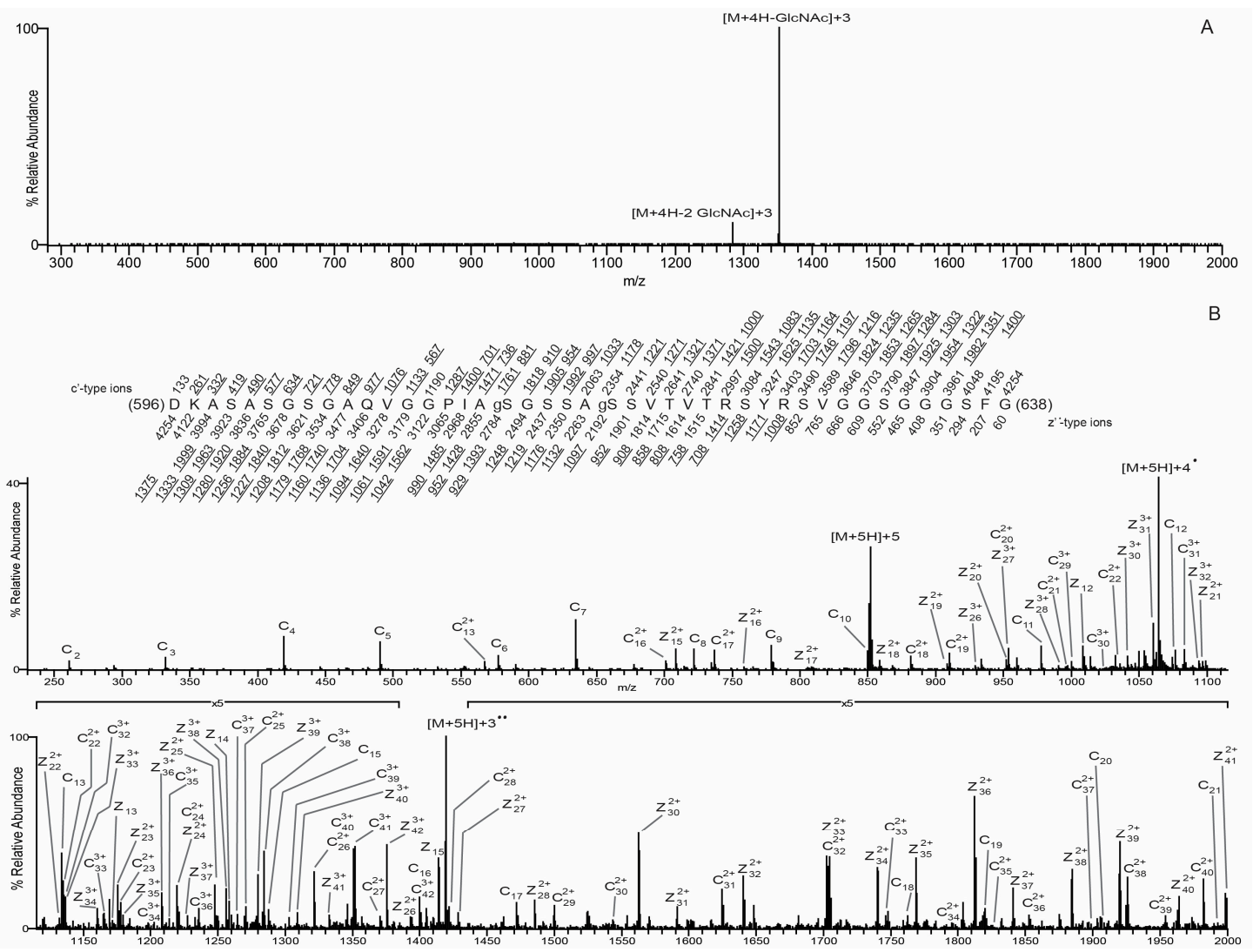

Figure 5. O-GlcNAc site mapping on the S612A/T643A-mutated mature lamin A tail via liquid chromatography-MS/MS. (A) CAD MS/MS spectrum recorded on the $(\mathrm{M}+4 \mathrm{H})^{4+}$ ions $(\mathrm{m} / z 1064.2561)$ of the di-GlcNAcylated peptide DKASASGSGAQVGGPIAgSGSSAgSSVTVTRSYRSVGGSGGGFG. The CAD spectrum contains the charge-reduced ions minus the loss of 1GlcNAc, $203 \mathrm{Da}$, at $m / z$ 1351, and the charge-reduced ion minus the loss of 2 GlcNAc residues, $406 \mathrm{Da}$, at $\mathrm{m} / z$ 1284; (B) an ETD MS/MS spectrum recorded on the $[\mathrm{M}+5 \mathrm{H}]^{5+}$ ions $(\mathrm{m} / \mathrm{z}$ 852.0084) of the di-GlcNAcylated peptide DKASASGSGAQVGGPIAgSGSSAgSSVTVTRSYRSVGGSGGGFG. Predicted product ions of types c'and $z^{\prime \bullet}$ - are listed above and below the peptide sequence, respectively. Singly charged ions are listed as monoisotopic masses; doubly and triply charged ions are listed as average masses. ETD product ions are labeled in the ETD spectrum. Observed product ions are underlined and are sufficient to define the $O-G l c N A c$ residues at Ser612 and Ser618, indicated by 'gS' in the amino acid sequence.

The $\Delta 35$ tail, with nine hypothetical sites (see Figure $6 \mathrm{~A}$ ), was modified surprisingly inefficiently: $97.7 \%$ of peptides were unmodified, with only single modifications detected at either $\mathrm{S} 612(<3 \%$ of peptide 596-664) or less frequently at S601 or S618 (Figure 3A,B). Peptides that included residue S613 were recovered, but unmodified, supporting the hypothesis that $\Delta 35$ greatly impairs substrate recognition or modification by OGT in vitro.

These results identify residues 601-645 as a broadly defined O-GlcNAc 'sweet spot' (Figure 6A), since OGT targeted this region robustly even when two abundant sites (S612 and T643) were missing ('AA' mutant; Figures $2 \mathrm{~B}$ and $3 \mathrm{~B}$ ). This sweet spot overlaps the region required for ZMPSTE24-dependent cleavage of prelamin A, raising the possibility that OGT might influence prelamin A maturation. However, the 'sweet spot' is also a permanent feature of mature lamin A filaments (Figure 7), suggesting OGT regulates roles unique to lamin A. 


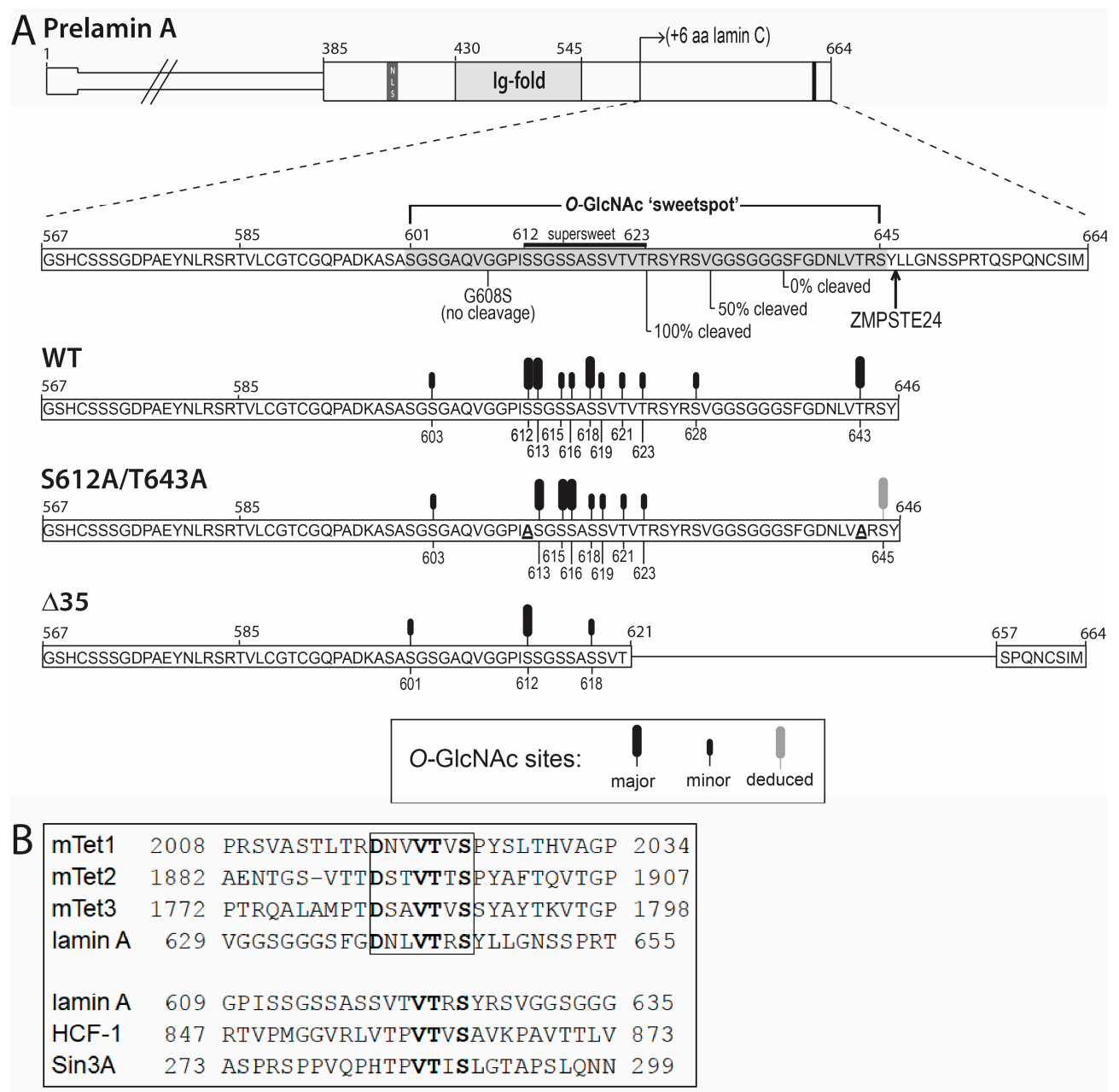

Figure 6. Schematic of lamin A tail polypeptides showing identified O-GlcNAc sites. (A) Schematic diagram of full-length prelamin A and the three recombinant lamin A tail fragments (wildtype-WT, S612A/T643A, 135 ) analyzed by mass spectrometry, all of which started with residue 385. All identified $\mathrm{O}$-GlcNAc sites are located in the C-terminal region unique to prelamin A, expanded below (dotted lines) to show the amino acid sequence. Abundant or less-abundant $O$-GlcNAc sites are symbolized by large ('major') or small ('minor') black rods, respectively. The ZMPSTE24-dependent proteolytic cleavage site is indicated. The starting points of fragments that were cleaved by ZMPSTE24 with 100\%, $\sim 50 \%$, or $0 \%$ efficiency in cells [41] are indicated below the sequence. Mutation G608S is sufficient to block cleavage in a different assay [42]. The region targeted by OGT in both wildtype and mutated lamin A tails (residues 601-645) is broadly designated the 'sweet spot', and includes 'supersweet' residues 612-623 (O-GlcNAc detected at every Ser and Thr); (B) amino acid sequence of the OGT-binding region in mouse Tet1 compared to homologous regions of conspecific Tet2 and Tet3 [43], two regions in human lamin A, and human HCF-1 and Sin3A. Bold residues are important for mTet1 binding to OGT [43]. Box indicates best conservation between mTet proteins and human lamin A residues 639-645. Human protein sequences were aligned against the consensus sequence found in mouse Tet1 using EMBOSS water pairwise alignment tool v.6.6.0 under default conditions for short sequence alignments (gap penalty: 10.0, extend penalty: 0.5). The upstream $\underline{\text { VTX }} \underline{\mathbf{S}}$ motif in lamin A (residues 609-635) was aligned manually against HCF-1 and Sin3A.

\section{Discussion}

Lamin glycosylation was first suggested nearly 30 years ago [44]. The nature of this modification was unknown until O-GlcNAc sites were identified in mitotic HeLa cells (S612 and T643; [19]) and mouse brains (sites S611 and S613, homologous to human S612; [45]). Our evidence that endogenous 
lamin A is O-GlcNAcylated in human hepatoma cells and mouse liver demonstrates biological OGT targeting of lamin A in liver. However, further studies are needed to identify O-GlcNAc sites in liver and explore their biological impact. Our biochemical analysis shows that OGT modifies lamin A tails selectively and robustly in vitro. Interestingly, all 13 identified primary and 'compensatory' O-GlcNAc sites are located within a 'sweet spot' (residues 601-645) unique to mature lamin A. This region includes 'super-sweet' residues 612-623, where O-GlcNAc was detected on every available Ser and Thr (Figure 6A). Two of our most abundant in vitro O-GlcNAc sites, S612 and T643, were previously reported in mitotic HeLa cells [19] and one was also seen in mouse brain [45], strongly supporting their biological relevance. However, their functional significance in mitosis or the brain remain completely unstudied. Our results also independently confirm two previously reported in vitro sites: S623 and S628 [46]. We further identified seven novel in vitro $O$-GlcNAc sites in mature wildtype human lamin A (S603, S613, S615, S616, S618, S619, and T621) and two novel compensatory sites: S601 (identified in $\Delta 35$ ) and S645 (identified in the S612A/T643A mutant). Our results do not rule out possible O-GlcNAc sites in the neck or Ig-fold domains, because we recovered the majority of-but not all-Ser/Thr-containing peptides from these regions. However, the lack of $O$-GlcNAcylation of either the $\Delta 50, \Delta 90$, or lamin $C$ tails strongly implies that OGT selectively targets residues 601-645 in the lamin A tail. One limitation of this study is that we did not examine the head or rod domains, or precursor residues 647-664. These regions warrant further study, because residue T91, in the coil-1B domain shared by all A-type lamins [47], is O-GlcNAc-modified in human embryonic stem cells [48].

A

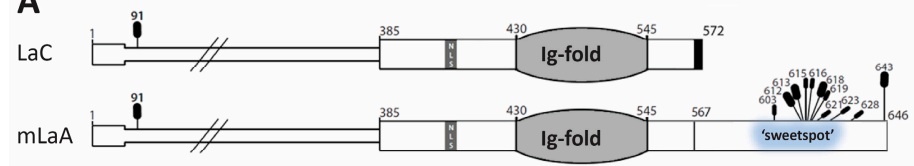

B

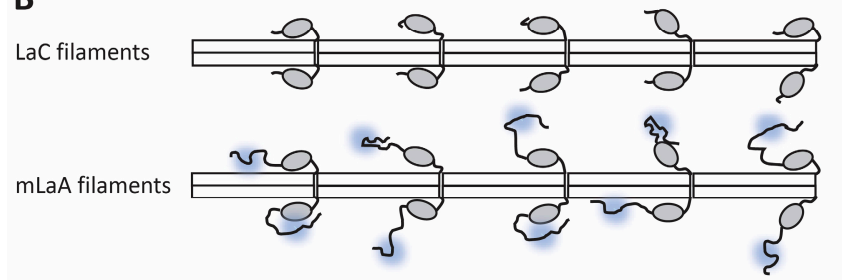

Figure 7. Schematic of mature lamin A and lamin C proteins, and filaments. (A) Schematic of the lamin A and lamin C proteins, which have identical residues 1-566, showing all currently identified O-GlcNAc sites. The Ig-fold is shaded gray; black indicates the short C-terminal region unique to lamin C. Long vs. short black ovals indicate greater or lesser abundance at each identified $O$-GlcNAc site, determined here for the lamin A tail (see text). The O-GlcNAc-modified region ('sweetspot') is highlighted in yellow, for comparison to panel B. Whether the O-GlcNAc site at T91 identified in embryonic stem cells [48] is present on both lamins (as depicted here), or limited to one type, is unknown; (B) molecular impact on filaments formed by lamin A versus lamin C. Competing or synergistic O-GlcNAc and phosphate modifications are predicted to drive different conformations of the lamin A tail, some of which may sterically block access to the Ig-fold domain (gray).

\subsection{Most O-GlcNAc Sites in Lamin A Are Not Predicted by Current Algorithms}

Substrate recognition by OGT is complex, involving both its TPR (protein-protein interaction) and catalytic domains, and can be influenced by post-translational modifications and partners [23,49]. There is no strict consensus site for O-GlcNAc modification [49]. For example, a study of pre-selected 13-mer peptides showed that $O$-GlcNAc sites are influenced by size and conformational restrictions in the -3 to +2 positions $[46,50]$, and reported O-GlcNAc modifications at three sites (T623, S625, and S628) in lamin A peptide ${ }^{618}$ SSVTVIR $\underline{S} Y R \underline{S V G}{ }^{630}$ and at one site (T399) in lamin B1 peptide ${ }^{389}$ KLSPSPSSRVTVS $^{401}$ [46]. Even though our lamin B1 tail polypeptide included T399, O-GlcNAcylation 
was not detected (Figure 2B), possibly because this fragment began at residue 394 and was likely insufficient for OGT recognition. For lamin A, we identified T623 and S628 (but not S625) as low-abundance sites, in the context of our much longer (>250-residue) tail polypeptides. Overall, very few identified $O$-GlcNAc sites in lamin A were predicted by the Pathak et al. (2015) [46] consensus. A shorter consensus, proposed by Liu and colleagues [51], fared slightly better: most 'sweet spot' sites match at positions -1 and +2 , but only three of our 13 sites match this consensus at position -2 .

In agreement with Jochmann and colleagues [49], many sites on lamin A were not predicted. For example, OGTsite [52] predicted three known sites (S612, T623, and T643), and three sites we did not detect. The YinOYang O-GlcNAc prediction server (http:/ / www.cbs.dtu.dk/services/YinOYang [53]) strongly predicted two identified sites (S612 and T621), weakly predicted five identified sites (S603, S613, S615, S618, and T623), failed to predict five sites (T91, S616, S619, S628, and T643; 42\% false negative rate), and predicted eight other tail sites we did not detect. O-GlcNAcPRED [54] predicted only two sites (both known: S612 and T643) at higher stringency; at lower stringency, this program predicted one more identified site (S601) plus three tail sites we did not detect. We suggest that O-GlcNAc sites identified in long polypeptides, rather than peptides, will be critical to improving predictive algorithms and understanding the molecular basis for OGT modifications at two or more adjoining residues, as seen for lamin A (this work) and its nuclear membrane partner, emerin [55].

\subsection{The 'Sweet Spot' in Relation to the Site of ZPMSTE24-Dependent Cleavage}

Figure 6A shows the identified O-GlcNAc sites in relation to published constructs, expressed as GFP-fusions, that were cleaved by ZMPSTE24 with either 100\% efficiency ('41-mer'; residues 624-664), 50\% efficiency ('31-mer'; residues 634-664), or not cleaved ('29-mer'; residues 636-664) in human embryonic kidney (HEK293) cells [41]. The 'super-sweet' region directly borders the 41-mer region sufficient for ZMPSTE24-dependent cleavage of prelamin A (Figure 6A). Upstream residues might also influence maturation, since a G608S substitution blocks FLAG-prelamin A cleavage in mouse embryonic fibroblasts [42]. Speculatively, OGT access to prelamin A might be influenced by hypothetical OGT association with Zmpste24 [56] ('PPI Finder' algorithm). Whether OGT modifies prelamin A-specific residues 647-664, or influences lamin A maturation, are open questions.

\subsection{Second Role for Residues Near the ZMPSTE24-Dependent Cleavage Site}

We were puzzled by progeria-causing deletion $\Delta 35$, which retained nine potential $O$-GlcNAc sites (including seven of eight 'supersweet' sites), but remained $97.7 \%$ unmodified in vitro (Figure 3B). Wondering if OGT might associate with this region, either during substrate recognition or independently as a hypothetical partner, we performed pairwise protein sequence alignments of lamin A to five proteins that bind OGT directly as partners (Figure 6B): Tet1 [43], Tet2 [57], Tet3 [58], HCF-1 [59], and transcription regulator Sin3A, which recruits OGT to promoters [23,60]. Triple Ala-substitution mutagenesis of mouse Tet1, in particular, identified a motif in which four residues (DNV $\underline{\text { VTV }}$ ) were critical for binding to OGT [43]. All four critical residues are conserved in conspecific Tet2 and Tet3 [43], and in human lamin A residues 639-645 (DNLVTR; boxed in Figure 6B), which adjoin the ZPMSTE24-dependent cleavage site (Figure 6A). Whether these four residues are also important for cleavage is unknown. We found that a similar motif with three of four critical residues conserved (VTRS) is present in human HCF-1, Sin3A, and lamin A residues 622-625, which adjoin the 'supersweet' region (Figure $6 \mathrm{~B}$ ). Both motifs are removed by $\Delta 35$, which deletes residues 622-656 (Figure 6A). Whether lamin A associates functionally with OGT as a partner, in addition to being modified by OGT, is an open and challenging question for future work (Levine and Walker, 2016). Collectively, our findings provide novel insight into progeria mechanisms by predicting a second molecular consequence of the $\Delta 50$ deletion: loss of OGT-dependent regulation. 
4.4. Selective OGT Targeting of Lamin A as a Mechanism for Separate Functions and Differential Regulation of Lamin A versus Lamin C

The discovery that lamin A and lamin $\mathrm{C}$ form separate filaments is so new and unexpected $[61,62]$ that few studies have even attempted to distinguish one from the other. We found that OGT selectively modifies the tail domain of mature lamin A, not lamin C, in vitro, suggesting the intrinsically-disordered 'tail' of mature lamin A is uniquely controlled by OGT (Figure 7A). These results add to growing evidence for functional specialization of lamin A versus lamin $\mathrm{C}$ filaments (Figure 7B). For example, lamin C specifically associates with nuclear pore complexes [62]. Specialization is also evident in the brain and in metabolism. Lamin $\mathrm{C}$ predominates in neurons, where mRNAs encoding prelamin A are eliminated by a specific microRNA [63]. When compared with wildtype controls, mice that express lamin $C$ as their only A-type lamin have significantly longer lifespans, despite accumulating white fat and developing abdominal tumors that limited their lifespan; these mice also have reduced rates of metabolism and respiration, fewer mitochondria, higher fasting insulin levels, and higher blood glucose levels [64]. Mice that express mature lamin A only have nuclear shape defects in fibroblasts, but otherwise normal body weight, health, and fertility [65], implying appropriate regulation of mature lamin A. A-type lamins are linked to the mTOR pathway, which senses glucose and other nutrients to promote biosynthetic pathways, and inhibit or limit catabolic (breakdown) pathways, including autophagy [66-68]. Autophagy is significantly elevated in lmna-mutated cells $[69,70]$. Mice that express H222P-mutated lmna in the heart have elevated AKT and mTOR signaling that leads to cardiomyopathy and impaired fasting-induced autophagy [71]. These phenotypes are ameliorated by mTOR inhibitors, suggesting an A-type lamin(s) normally dampens mTOR signaling [72-74]. We speculate that OGT, which responds independently to nutrient stress, specifically influences lamin A under these conditions.

What happens if OGT cannot modify the lamin A tail? Two elements are lost by deletion in 'classic' ( $\triangle 50)$ HGPS: functions specifically mediated by the lamin A tail, and OGT-dependent control of these functions. Neither element is likely to be restored by therapies that block farnesylation. Treating HGPS patients with the farnesyltransferase inhibitor Lonafarnib improved weight gain [18] and reduced prevalence of stroke [75], but did not affect other parameters, including insulin resistance (seen in $35 \%$ of patients; [18]). We found that progeria-associated deletions either abolished $(\Delta 50)$ or greatly reduced $(\Delta 35)$ lamin A modification by OGT in vitro. Interestingly, three missense variants that perturb metabolism are located in the 'sweet spot': p.G602S (insulin resistance syndrome [8]; type 2 diabetes [76]), p.G631D (metabolic syndrome; [12]), and p.R644C (multiple phenotypes; [77]). Variant p.L92F, identified in an obese patient with severe metabolic syndrome [13], adjoins the reported $O$-GlcNAc site at T91 [48]. However more work is needed to decipher mechanisms, since variants that affect metabolism, like those that cause other laminopathies, are located throughout the polypeptide.

\subsection{Potential Impacts of O-GlcNAc on Mature Lamin A}

OGT and lamin A each have global roles that include signaling, epigenetic regulation, and mitosis [3,78,79]. For example, lamins and key partners (LEM-domain proteins and BANF1) are required to dynamically rebuild nuclear structure during exit from mitosis [80-84]. Similarly, OGT is required for dividing cells to survive [21,23]. Lamins have many reported modifications, the best understood of which is phosphorylation. From this perspective, we note that 10 of our 12 total identified $O$-GlcNAc sites can be phosphorylated in a variety of cell types or conditions $[37,38]$ (www.phosphosite.org). To our knowledge, O-GlcNAc is the only reported modification of lamin A residues T91 [48] and T621 (this work). Our findings suggest that lamin A-like cytoplasmic intermediate filaments-is specifically and dynamically regulated by crosstalk between OGT and multiple kinases [85].

$O-G l c N A c$ and phosphate modifications can profoundly alter the conformations of intrinsically disordered polypeptides [86-88], with consequences for partners. Partners that bind the unstructured region of lamin A, besides ZPMSTE24 (discussed above), include SUN1 [89], Narf, RBBP4, PKC $\alpha$, 
and actin [37]. Certain partners identified in a yeast two-hybrid screen are disrupted by disease-associated missense variants in the 'sweet spot', and might therefore be influenced by $O$-GlcNAc modifications. These partners include LAP1 $\beta$ (disrupted by lamin A variant p.G602S), ZNF3 (disrupted by p.G602S, p.G608S, p.T623S, p.R644C), MORF4L1 (disrupted by p.G602S, p.G608S, p.T623S), Cyclin G1 (disrupted by p.G602S, p.G608S, p.R644C), and CENP-P (disrupted by p.R644C) [90]. We speculate that 'sweet-spot' modifications might also influence association with AIMP3, a cytoplasmic scaffolding protein that can also enter the nucleus and act as a tumor suppressor [91,92]. AIMP3 binds directly to residues 641-647 in the 'sweet spot' of mature lamin A [91]. AIMP3 recruits Siah1 (an E3 ubiquitin ligase) and triggers selective degradation of mature lamin A to promote senescence [91,92]. In the context of lamin A filaments, modifications by OGT and kinases might dictate a spectrum of tail conformations unique to lamin A (modeled in Figure 7B), influencing various partners either directly or via access to the Ig-fold domain (Figure 7B), as suggested for actin [31] and Tpr [93].

This study is significant because it identifies a novel molecular pathway that may profoundly influence lamin A function. Our results suggest OGT-dependent control of lamin A is perturbed by progeria-associated deletions. As a master regulator of metabolism [94,95], OGT has the potential to misregulate wildtype lamin A in response to nutrient (including glucose) stress or other stresses. The physiological significance of lamin A tail O-GlcNAcylation, whether it influences signaling, transcription, 3D genome organization [96-99], or novel roles, and proposed crosstalk with phosphorylation, all remain to be determined in future studies.

Supplementary Materials: The following are available online at http:/ / www.mdpi.com/2073-4409/7/5/44/s1, Figure S1: Peptide mapping of the lamin A/C epitopes recognized by antibody 5G4 and antibody L1293.

Author Contributions: D.N.S. and K.L.W. conceived and designed the study, analyzed results, and drafted the paper, with supporting analysis and figure preparation by Q.F., L.M.G.-W., A.W., T.D. and Y.G. Q.F., L.M.G.-W., C.R.C., A.F., and S.B.P. designed, performed, and analyzed supporting and/or final experiments for Figure 1. C.R.C. designed and performed the experiments in Supplemental Figure 1. D.N.S. and Y.G. performed and analyzed the experiments in Figure 2. D.N.S. prepared samples for Figures 3-5. A.W., J.S., and D.F.H. designed, performed, and analyzed the experiments in Figures 3-5. T.D., A.F., D.N.S. and K.L.W. contributed to Figures 6 and 7. All authors contributed intellectually, reviewed results, and approved the final manuscript.

Acknowledgments: We gratefully acknowledge funding from the Progeria Research Foundation (K.L.W.), Johns Hopkins University Claude D. Pepper Older Americans Independence Center National Institutes of Health NIA P30AG021334 (K.L.W.), US-Israel Binational Science Foundation (Y.G. and K.L.W.), National Institutes of Health T32GM007445 (D.N.S.), National Institutes of Health GM037537 (D.F.H.), Research Council of Norway (C.R.C., Q.F., L.M.G.-W.), and the University of Oslo and Anders Jahre Foundation (Q.F., L.M.G.-W.). We thank Jason Berk, Cliff Jenkins-Houk, and Joana Eid for early contributions to this project, and Natasha Zachara, Gerald Hart, and NHLBI Core C4 (Johns Hopkins School of Medicine) for purified OGT enzyme and O-GlcNAc antibodies.

Conflicts of Interest: The authors declare no conflict of interest.

\section{References}

1. Simon, D.N.; Wilson, K.L. The nucleoskeleton as a genome-associated dynamic 'network of networks'. Nat. Rev. Mol. Cell Biol. 2011, 12, 695-708. [CrossRef] [PubMed]

2. Worman, H.J.; Schirmer, E.C. Nuclear membrane diversity: Underlying tissue-specific pathologies in disease? Curr. Opin. Cell Biol. 2015, 34, 101-112. [CrossRef] [PubMed]

3. Gruenbaum, Y.; Foisner, R. Lamins: Nuclear intermediate filament proteins with fundamental functions in nuclear mechanics and genome regulation. Annu. Rev. Biochem. 2015, 84, 131-164. [CrossRef] [PubMed]

4. Dittmer, T.A.; Misteli, T. The lamin protein family. Genome Biol. 2011, 12, 222. [CrossRef] [PubMed]

5. Peter, A.; Stick, R. Evolution of the lamin protein family: What introns can tell. Nucleus 2012, 3, 44-59. [CrossRef] [PubMed]

6. Koreny, L.; Field, M.C. Ancient eukaryotic origin and evolutionary plasticity of nuclear lamina. Genome Biol. Evol. 2016, 8, 2663-2671. [CrossRef] [PubMed]

7. Burke, B.; Stewart, C.L. Functional architecture of the cell's nucleus in development, aging, and disease. Curr. Top. Dev. Biol. 2014, 109, 1-52. [PubMed] 
8. Young, J.; Morbois-Trabut, L.; Couzinet, B.; Lascols, O.; Dion, E.; Bereziat, V.; Feve, B.; Richard, I.; Capeau, J.; Chanson, P.; et al. Type A insulin resistance syndrome revealing a novel lamin A mutation. Diabetes 2005, 54, 1873-1878. [CrossRef] [PubMed]

9. Guenantin, A.C.; Briand, N.; Bidault, G.; Afonso, P.; Bereziat, V.; Vatier, C.; Lascols, O.; Caron-Debarle, M.; Capeau, J.; Vigouroux, C. Nuclear envelope-related lipodystrophies. Semin. Cell Dev. Biol. 2014, 29, $148-157$. [CrossRef] [PubMed]

10. Vigouroux, C.; Magre, J.; Vantyghem, M.C.; Bourut, C.; Lascols, O.; Shackleton, S.; Lloyd, D.J.; Guerci, B.; Padova, G.; Valensi, P.; et al. Lamin A/C gene: Sex-determined expression of mutations in Dunnigan-type familial partial lipodystrophy and absence of coding mutations in congenital and acquired generalized lipoatrophy. Diabetes 2000, 49, 1958-1962. [CrossRef] [PubMed]

11. Rizza, R.A. Pathogenesis of fasting and postprandial hyperglycemia in type 2 diabetes: Implications for therapy. Diabetes 2010, 59, 2697-2707. [CrossRef] [PubMed]

12. Dutour, A.; Roll, P.; Gaborit, B.; Courrier, S.; Alessi, M.C.; Tregouet, D.A.; Angelis, F.; Robaglia-Schlupp, A.; Lesavre, N.; Cau, P.; et al. High prevalence of laminopathies among patients with metabolic syndrome. Hum. Mol. Genet. 2011, 20, 3779-3786. [CrossRef] [PubMed]

13. Decaudain, A.; Vantyghem, M.C.; Guerci, B.; Hecart, A.C.; Auclair, M.; Reznik, Y.; Narbonne, H.; Ducluzeau, P.H.; Donadille, B.; Lebbe, C.; et al. New metabolic phenotypes in laminopathies: LMNA mutations in patients with severe metabolic syndrome. J. Clin. Endocrinol. Metab. 2007, 92, 4835-4844. [CrossRef] [PubMed]

14. Merideth, M.A.; Gordon, L.B.; Clauss, S.; Sachdev, V.; Smith, A.C.; Perry, M.B.; Brewer, C.C.; Zalewski, C.; Kim, H.J.; Solomon, B.; et al. Phenotype and course of Hutchinson-Gilford progeria syndrome. N. Engl. J. Med. 2008, 358, 592-604. [CrossRef] [PubMed]

15. Eriksson, M.; Brown, W.T.; Gordon, L.B.; Glynn, M.W.; Singer, J.; Scott, L.; Erdos, M.R.; Robbins, C.M.; Moses, T.Y.; Berglund, P.; et al. Recurrent de novo point mutations in lamin A cause Hutchinson-Gilford progeria syndrome. Nature 2003, 423, 293-298. [CrossRef] [PubMed]

16. Fukuchi, K.; Katsuya, T.; Sugimoto, K.; Kuremura, M.; Kim, H.D.; Li, L.; Ogihara, T. LMNA mutation in a 45 year old Japanese subject with Hutchinson-Gilford progeria syndrome. J. Med. Genet. 2004, 41 , e67. [CrossRef] [PubMed]

17. Vidak, S.; Foisner, R. Molecular insights into the premature aging disease progeria. Histochem. Cell Biol. 2016, 145, 401-417. [CrossRef] [PubMed]

18. Gordon, L.B.; Kleinman, M.E.; Miller, D.T.; Neuberg, D.S.; Giobbie-Hurder, A.; Gerhard-Herman, M.; Smoot, L.B.; Gordon, C.M.; Cleveland, R.; Snyder, B.D.; et al. Clinical trial of a farnesyltransferase inhibitor in children with Hutchinson-Gilford progeria syndrome. Proc. Natl. Acad. Sci. USA 2012, 109, 16666-16671. [CrossRef] [PubMed]

19. Wang, Z.; Udeshi, N.D.; Slawson, C.; Compton, P.D.; Sakabe, K.; Cheung, W.D.; Shabanowitz, J.; Hunt, D.F.; Hart, G.W. Extensive crosstalk between $O-G l c N A c y l a t i o n$ and phosphorylation regulates cytokinesis. Sci. Signal. 2010, 3, ra2. [CrossRef] [PubMed]

20. Hart, G.W.; Copeland, R.J. Glycomics hits the big time. Cell 2010, 143, 672-676. [CrossRef] [PubMed]

21. Shafi, R.; Iyer, S.P.; Ellies, L.G.; O’Donnell, N.; Marek, K.W.; Chui, D.; Hart, G.W.; Marth, J.D. The O-GlcNAc transferase gene resides on the $\mathrm{X}$ chromosome and is essential for embryonic stem cell viability and mouse ontogeny. Proc. Natl. Acad. Sci. USA 2000, 97, 5735-5739. [CrossRef] [PubMed]

22. Hart, G.W. Minireview series on the thirtieth anniversary of research on $O$-GlcNAcylation of nuclear and cytoplasmic proteins: Nutrient regulation of cellular metabolism and physiology by O-GlcNAcylation. J. Biol. Chem. 2014, 289, 34422-34423. [CrossRef] [PubMed]

23. Levine, Z.G.; Walker, S. The biochemistry of $O$-GlcNAc transferase: Which functions make it essential in mammalian cells? Annu. Rev. Biochem. 2016, 85, 631-657. [CrossRef] [PubMed]

24. Bond, M.R.; Hanover, J.A. O-GlcNAc cycling: A link between metabolism and chronic disease. Annu. Rev. Nutr. 2013, 33, 205-229. [CrossRef] [PubMed]

25. Copeland, R.J.; Bullen, J.W.; Hart, G.W. Cross-talk between GlcNAcylation and phosphorylation: Roles in insulin resistance and glucose toxicity. Am. J. Physiol. Endocrinol. Metab. 2008, 295, E17-E28. [CrossRef] [PubMed]

26. Hardiville, S.; Hart, G.W. Nutrient regulation of signaling, transcription, and cell physiology by O-GlcNAcylation. Cell Metab. 2014, 20, 208-213. [CrossRef] [PubMed] 
27. Jensen, R.V.; Zachara, N.E.; Nielsen, P.H.; Kimose, H.H.; Kristiansen, S.B.; Botker, H.E. Impact of O-GlcNAc on cardioprotection by remote ischaemic preconditioning in non-diabetic and diabetic patients. Cardiovasc. Res. 2013, 97, 369-378. [CrossRef] [PubMed]

28. Ramirez-Correa, G.A.; Jin, W.; Wang, Z.; Zhong, X.; Gao, W.D.; Dias, W.B.; Vecoli, C.; Hart, G.W.; Murphy, A.M. O-linked GlcNAc modification of cardiac myofilament proteins: A novel regulator of myocardial contractile function. Circ. Res. 2008, 103, 1354-1358. [CrossRef] [PubMed]

29. Zhang, K.; Yin, R.; Yang, X. O-GlcNAc: A bittersweet switch in liver. Front. Endocrinol. (Lausanne) 2014, 5, 221. [CrossRef] [PubMed]

30. Frank, R.; Overwin, H. Spot synthesis. Epitope analysis with arrays of synthetic peptides prepared on cellulose membranes. Methods Mol. Biol. 1996, 66, 149-169. [PubMed]

31. Simon, D.N.; Zastrow, M.S.; Wilson, K.L. Direct actin binding to A- and B-type lamin tails and actin filament bundling by the lamin a tail. Nucleus 2010, 1, 264-272. [CrossRef] [PubMed]

32. Lazarus, M.B.; Nam, Y.; Jiang, J.; Sliz, P.; Walker, S. Structure of human O-GlcNAc transferase and its complex with a peptide substrate. Nature 2011, 469, 564-567. [CrossRef] [PubMed]

33. Udeshi, N.D.; Compton, P.D.; Shabanowitz, J.; Hunt, D.F.; Rose, K.L. Methods for analyzing peptides and proteins on a chromatographic timescale by electron-transfer dissociation mass spectrometry. Nat. Protoc. 2008, 3, 1709-1717. [CrossRef] [PubMed]

34. Earley, L.; Anderson, L.C.; Bai, D.L.; Mullen, C.; Syka, J.E.; English, A.M.; Dunyach, J.J.; Stafford, G.C., Jr.; Shabanowitz, J.; Hunt, D.F.; et al. Front-end electron transfer dissociation: A new ionization source. Anal. Chem. 2013, 85, 8385-8390. [CrossRef] [PubMed]

35. Geer, L.Y.; Markey, S.P.; Kowalak, J.A.; Wagner, L.; Xu, M.; Maynard, D.M.; Yang, X.; Shi, W.; Bryant, S.H. Open mass spectrometry search algorithm. J. Proteome Res. 2004, 3, 958-964. [CrossRef] [PubMed]

36. Like, A.A.; Rossini, A.A. Streptozotocin-induced pancreatic insulitis: New model of diabetes mellitus. Science 1976, 193, 415-417. [CrossRef] [PubMed]

37. Simon, D.N.; Wilson, K.L. Partners and post-translational modifications of nuclear lamins. Chromosoma 2013, 122, 13-31. [CrossRef] [PubMed]

38. Kochin, V.; Shimi, T.; Torvaldson, E.; Adam, S.A.; Goldman, A.; Pack, C.G.; Melo-Cardenas, J.; Imanishi, S.Y.; Goldman, R.D.; Eriksson, J.E. Interphase phosphorylation of lamin A. J. Cell Sci. 2014, 127, $2683-2696$. [CrossRef] [PubMed]

39. Navarro, C.L.; De Sandre-Giovannoli, A.; Bernard, R.; Boccaccio, I.; Boyer, A.; Genevieve, D.; Hadj-Rabia, S.; Gaudy-Marqueste, C.; Smitt, H.S.; Vabres, P.; et al. Lamin A and ZMPSTE24 (FACE-1) defects cause nuclear disorganization and identify restrictive dermopathy as a lethal neonatal laminopathy. Hum. Mol. Genet. 2004, 13, 2493-2503. [CrossRef] [PubMed]

40. Krimm, I.; Ostlund, C.; Gilquin, B.; Couprie, J.; Hossenlopp, P.; Mornon, J.P.; Bonne, G.; Courvalin, J.C.; Worman, H.J.; Zinn-Justin, S. The Ig-like structure of the C-terminal domain of lamin A/C, mutated in muscular dystrophies, cardiomyopathy, and partial lipodystrophy. Structure 2002, 10, 811-823. [CrossRef]

41. Barrowman, J.; Hamblet, C.; Kane, M.S.; Michaelis, S. Requirements for efficient proteolytic cleavage of prelamin a by ZMPSTE24. PLoS ONE 2012, 7, e32120. [CrossRef] [PubMed]

42. Casasola, A.; Scalzo, D.; Nandakumar, V.; Halow, J.; Recillas-Targa, F.; Groudine, M.; Rincon-Arano, H. Prelamin A processing, accumulation and distribution in normal cells and laminopathy disorders. Nucleus 2016, 7, 84-102. [CrossRef] [PubMed]

43. Hrit, J.; Li, C.; Martin, E.A.; Simental, E.; Goll, M.; Panning, B. OGT binds a conserved c-terminal domain of TET1 to regulate TET1 activity and function in development. bioRxiv 2017, 125419. [CrossRef]

44. Ferraro, A.; Eufemi, M.; Cervoni, L.; Marinetti, R.; Turano, C. Glycosylated forms of nuclear lamins. FEBS Lett. 1989, 257, 241-246. [CrossRef]

45. Alfaro, J.F.; Gong, C.X.; Monroe, M.E.; Aldrich, J.T.; Clauss, T.R.; Purvine, S.O.; Wang, Z.; Camp, D.G., 2nd; Shabanowitz, J.; Stanley, P.; et al. Tandem mass spectrometry identifies many mouse brain O-GlcNAcylated proteins including EGF domain-specific O-GlcNAc transferase targets. Proc. Natl. Acad. Sci. USA 2012, 109, 7280-7285. [CrossRef] [PubMed]

46. Pathak, S.; Alonso, J.; Schimpl, M.; Rafie, K.; Blair, D.E.; Borodkin, V.S.; Schuttelkopf, A.W.; Albarbarawi, O.; van Aalten, D.M. The active site of O-GlcNAc transferase imposes constraints on substrate sequence. Nat. Struct. Mol. Biol. 2015, 22, 744-750. [CrossRef] [PubMed] 
47. Herrmann, H.; Kreplak, L.; Aebi, U. Isolation, characterization, and in vitro assembly of intermediate filaments. Methods Cell Biol. 2004, 78, 3-24. [PubMed]

48. Zhao, P.; Schulz, T.C.; Sherrer, E.S.; Weatherly, D.B.; Robins, A.J.; Wells, L. The human embryonic stem cell proteome revealed by multidimensional fractionation followed by tandem mass spectrometry. Proteomics 2015, 15, 554-566. [CrossRef] [PubMed]

49. Jochmann, R.; Holz, P.; Sticht, H.; Sturzl, M. Validation of the reliability of computational O-GlcNAc prediction. Biochim. Biophys. Acta 2014, 1844, 416-421. [CrossRef] [PubMed]

50. Schutkowski, M.; Reimer, U.; Panse, S.; Dong, L.; Lizcano, J.M.; Alessi, D.R.; Schneider-Mergener, J. High-content peptide microarrays for deciphering kinase specificity and biology. Angew. Chem. Int. Ed. Engl. 2004, 43, 2671-2674. [CrossRef] [PubMed]

51. Liu, X.; Li, L.; Wang, Y.; Yan, H.; Ma, X.; Wang, P.G.; Zhang, L. A peptide panel investigation reveals the acceptor specificity of $O$-GlcNAc transferase. FASEB J. 2014, 28, 3362-3372. [CrossRef] [PubMed]

52. Kao, H.J.; Huang, C.H.; Bretana, N.A.; Lu, C.T.; Huang, K.Y.; Weng, S.L.; Lee, T.Y. A two-layered machine learning method to identify protein O-GlcNAcylation sites with $O$-GlcNAc transferase substrate motifs. BMC Bioinform. 2015, 16 (Suppl. 18), S10. [CrossRef] [PubMed]

53. Gupta, R.; Brunak, S. Prediction of glycosylation across the human proteome and the correlation to protein function. Pac. Symp. Biocomput. 2002, 310-322. [CrossRef]

54. Jia, C.Z.; Liu, T.; Wang, Z.P. O-GlcNAcPRED: A sensitive predictor to capture protein O-GlcNAcylation sites. Mol. Biosyst. 2013, 9, 2909-2913. [CrossRef] [PubMed]

55. Berk, J.M.; Maitra, S.; Dawdy, A.W.; Shabanowitz, J.; Hunt, D.F.; Wilson, K.L. O-linked beta- $N$-acetylglucosamine $(\mathrm{O}-\mathrm{GlcNAc})$ regulates emerin binding to barrier to autointegration factor (BAF) in a chromatin- and lamin B-enriched "niche". J. Biol. Chem. 2013, 288, 30192-30209. [CrossRef] [PubMed]

56. He, M.; Wang, Y.; Li, W. Ppi finder: A mining tool for human protein-protein interactions. PLoS ONE 2009, 4, e4554. [CrossRef] [PubMed]

57. Chen, Q.; Chen, Y.; Bian, C.; Fujiki, R.; Yu, X. TET2 promotes histone O-GlcNAcylation during gene transcription. Nature 2013, 493, 561-564. [CrossRef] [PubMed]

58. Zhang, Q.; Liu, X.; Gao, W.; Li, P.; Hou, J.; Li, J.; Wong, J. Differential regulation of the ten-eleven translocation (TET) family of dioxygenases by $O$-linked beta- $N$-acetylglucosamine transferase (OGT). J. Biol. Chem. 2014, 289, 5986-5996. [CrossRef] [PubMed]

59. Lazarus, M.B.; Jiang, J.; Kapuria, V.; Bhuiyan, T.; Janetzko, J.; Zandberg, W.F.; Vocadlo, D.J.; Herr, W.; Walker, S. HCF-1 is cleaved in the active site of O-GlcNAc transferase. Science 2013, 342, 1235-1239. [CrossRef] [PubMed]

60. Yang, X.; Zhang, F.; Kudlow, J.E. Recruitment of O-GlcNAc transferase to promoters by corepressor mSin3A:

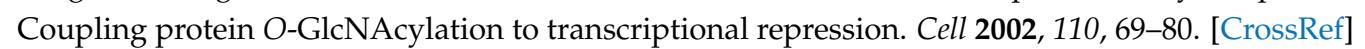

61. Shimi, T.; Kittisopikul, M.; Tran, J.; Goldman, A.E.; Adam, S.A.; Zheng, Y.; Jaqaman, K.; Goldman, R.D. Structural organization of nuclear lamins A, C, B1, and B2 revealed by superresolution microscopy. Mol. Biol. Cell 2015, 26, 4075-4086. [CrossRef] [PubMed]

62. Xie, W.; Chojnowski, A.; Boudier, T.; Lim, J.S.; Ahmed, S.; Ser, Z.; Stewart, C.; Burke, B. A-type lamins form distinct filamentous networks with differential nuclear pore complex associations. Curr. Biol. 2016, 26, 2651-2658. [CrossRef] [PubMed]

63. Jung, H.J.; Coffinier, C.; Choe, Y.; Beigneux, A.P.; Davies, B.S.; Yang, S.H.; Barnes, R.H., 2nd; Hong, J.; Sun, T.; Pleasure, S.J.; et al. Regulation of prelamin A but not lamin c by miR-9, a brain-specific microRNA. Proc. Natl. Acad. Sci. USA 2012, 109, E423-E431. [CrossRef] [PubMed]

64. Lopez-Mejia, I.C.; de Toledo, M.; Chavey, C.; Lapasset, L.; Cavelier, P.; Lopez-Herrera, C.; Chebli, K.; Fort, P.; Beranger, G.; Fajas, L.; et al. Antagonistic functions of LMNA isoforms in energy expenditure and lifespan. EMBO Rep. 2014, 15, 529-539. [CrossRef] [PubMed]

65. Coffinier, C.; Jung, H.J.; Li, Z.; Nobumori, C.; Yun, U.J.; Farber, E.A.; Davies, B.S.; Weinstein, M.M.; Yang, S.H.; Lammerding, J.; et al. Direct synthesis of lamin A, bypassing prelamin a processing, causes misshapen nuclei in fibroblasts but no detectable pathology in mice. J. Biol. Chem. 2010, 285, 20818-20826. [CrossRef] [PubMed]

66. Evangelisti, C.; Cenni, V.; Lattanzi, G. Potential therapeutic effects of the MTOR inhibitors for preventing ageing and progeria-related disorders. Br. J. Clin. Pharmacol. 2016, 82, 1229-1244. [CrossRef] [PubMed] 
67. Mendelsohn, A.R.; Larrick, J.W. Rapamycin as an antiaging therapeutic?: Targeting mammalian target of rapamycin to treat Hutchinson-Gilford progeria and neurodegenerative diseases. Rejuvenation Res. 2011, 14, 437-441. [CrossRef] [PubMed]

68. Shimobayashi, M.; Hall, M.N. Making new contacts: The mTOR network in metabolism and signalling crosstalk. Nat. Rev. Mol. Cell Biol. 2014, 15, 155-162. [CrossRef] [PubMed]

69. Park, Y.E.; Hayashi, Y.K.; Bonne, G.; Arimura, T.; Noguchi, S.; Nonaka, I.; Nishino, I. Autophagic degradation of nuclear components in mammalian cells. Autophagy 2009, 5, 795-804. [CrossRef] [PubMed]

70. Ramos, F.J.; Chen, S.C.; Garelick, M.G.; Dai, D.F.; Liao, C.Y.; Schreiber, K.H.; MacKay, V.L.; An, E.H.; Strong, R.; Ladiges, W.C.; et al. Rapamycin reverses elevated mTORC1 signaling in lamin A/C-deficient mice, rescues cardiac and skeletal muscle function, and extends survival. Sci. Transl. Med. 2012, 4, 144ra103. [CrossRef] [PubMed]

71. Choi, J.C.; Muchir, A.; Wu, W.; Iwata, S.; Homma, S.; Morrow, J.P.; Worman, H.J. Temsirolimus activates autophagy and ameliorates cardiomyopathy caused by lamin A/C gene mutation. Sci. Transl. Med. 2012, 4, 144ra102. [CrossRef] [PubMed]

72. Cattin, M.E.; Wang, J.; Weldrick, J.J.; Roeske, C.L.; Mak, E.; Thorn, S.L.; DaSilva, J.N.; Wang, Y.; Lusis, A.J.; Burgon, P.G. Deletion of MLIP (muscle-enriched A-type lamin-interacting protein) leads to cardiac hyperactivation of Akt/mammalian target of rapamycin (mTOR) and impaired cardiac adaptation. J. Biol. Chem. 2015, 290, 26699-26714. [CrossRef] [PubMed]

73. Choi, J.C.; Worman, H.J. Reactivation of autophagy ameliorates LMNA cardiomyopathy. Autophagy 2013, 9 , 110-111. [CrossRef] [PubMed]

74. Ramos, F.J.; Kaeberlein, M.; Kennedy, B.K. Elevated MTORC1 signaling and impaired autophagy. Autophagy 2013, 9, 108-109. [CrossRef] [PubMed]

75. Ullrich, N.J.; Kieran, M.W.; Miller, D.T.; Gordon, L.B.; Cho, Y.J.; Silvera, V.M.; Giobbie-Hurder, A.; Neuberg, D.; Kleinman, M.E. Neurologic features of Hutchinson-Gilford progeria syndrome after lonafarnib treatment. Neurology 2013, 81, 427-430. [CrossRef] [PubMed]

76. Florwick, A.; Dharmaraj, T.; Jurgens, J.; Valle, D.; Wilson, K.L. LMNA sequences of 60,706 unrelated individuals reveal 132 novel missense variants in A-type lamins and suggest a link between variant p.G602S and type 2 diabetes. Front. Genet. 2017, 8, 79. [CrossRef] [PubMed]

77. Rankin, J.; Auer-Grumbach, M.; Bagg, W.; Colclough, K.; Nguyen, T.D.; Fenton-May, J.; Hattersley, A.; Hudson, J.; Jardine, P.; Josifova, D.; et al. Extreme phenotypic diversity and nonpenetrance in families with the LMNA gene mutation R644C. Am. J. Med. Genet. A 2008, 146A, 1530-1542. [CrossRef] [PubMed]

78. Harwood, K.R.; Hanover, J.A. Nutrient-driven O-GlcNAc cycling-Think globally but act locally. J. Cell Sci. 2014, 127, 1857-1867. [CrossRef] [PubMed]

79. De Leeuw, R.; Gruenbaum, Y.; Medalia, O. Nuclear lamins: Thin filaments with major functions. Trends Cell Biol. 2017, 28, 34-45. [CrossRef] [PubMed]

80. Samwer, M.; Schneider, M.W.G.; Hoefler, R.; Schmalhorst, P.S.; Jude, J.G.; Zuber, J.; Gerlich, D.W. DNA cross-bridging shapes a single nucleus from a set of mitotic chromosomes. Cell 2017, 170, 956-972. [CrossRef] [PubMed]

81. Naetar, N.; Ferraioli, S.; Foisner, R. Lamins in the nuclear interior-Life outside the lamina. J. Cell Sci. 2017, 130, 2087-2096. [CrossRef] [PubMed]

82. Liu, J.; Lee, K.K.; Segura-Totten, M.; Neufeld, E.; Wilson, K.L.; Gruenbaum, Y. MAN1 and emerin have overlapping function(s) essential for chromosome segregation and cell division in Caenorhabditis elegans. Proc. Natl. Acad. Sci. USA 2003, 100, 4598-4603. [CrossRef] [PubMed]

83. Liu, J.; Rolef Ben-Shahar, T.; Riemer, D.; Treinin, M.; Spann, P.; Weber, K.; Fire, A.; Gruenbaum, Y. Essential roles for Caenorhabditis elegans lamin gene in nuclear organization, cell cycle progression, and spatial organization of nuclear pore complexes. Mol. Biol. Cell 2000, 11, 3937-3947. [CrossRef] [PubMed]

84. Margalit, A.; Segura-Totten, M.; Gruenbaum, Y.; Wilson, K.L. Barrier-to-autointegration factor is required to segregate and enclose chromosomes within the nuclear envelope and assemble the nuclear lamina. Proc. Natl. Acad. Sci. USA 2005, 102, 3290-3295. [CrossRef] [PubMed]

85. Snider, N.T.; Omary, M.B. Post-translational modifications of intermediate filament proteins: Mechanisms and functions. Nat. Rev. Mol. Cell Biol. 2014, 15, 163-177. [CrossRef] [PubMed] 
86. Chen, Y.X.; Du, J.T.; Zhou, L.X.; Liu, X.H.; Zhao, Y.F.; Nakanishi, H.; Li, Y.M. Alternative O-GlcNAcylation/O-phosphorylation of Ser16 induce different conformational disturbances to the $\mathrm{n}$ terminus of murine estrogen receptor beta. Chem. Biol. 2006, 13, 937-944. [CrossRef] [PubMed]

87. Roque, A.; Ponte, I.; Suau, P. Post-translational modifications of the intrinsically disordered terminal domains of histone H1: Effects on secondary structure and chromatin dynamics. Chromosoma 2017, 126, 83-91. [CrossRef] [PubMed]

88. Uversky, V.N. Intrinsic disorder here, there, and everywhere, and nowhere to escape from it. Cell. Mol. Life Sci. 2017, 74, 3065-3067. [CrossRef] [PubMed]

89. Crisp, M.; Liu, Q.; Roux, K.; Rattner, J.B.; Shanahan, C.; Burke, B.; Stahl, P.D.; Hodzic, D. Coupling of the nucleus and cytoplasm: Role of the LINC complex. J. Cell Biol. 2006, 172, 41-53. [CrossRef] [PubMed]

90. Dittmer, T.A.; Sahni, N.; Kubben, N.; Hill, D.E.; Vidal, M.; Burgess, R.C.; Roukos, V.; Misteli, T. Systematic identification of pathological lamin A interactors. Mol. Biol. Cell 2014, 25, 1493-1510. [CrossRef] [PubMed]

91. Tao, Y.; Fang, P.; Kim, S.; Guo, M.; Young, N.L.; Marshall, A.G. Mapping the contact surfaces in the lamin A:AIMP3 complex by hydrogen/deuterium exchange FT-ICR mass spectrometry. PLoS ONE 2017, 12, e0181869. [CrossRef] [PubMed]

92. Oh, Y.S.; Kim, D.G.; Kim, G.; Choi, E.C.; Kennedy, B.K.; Suh, Y.; Park, B.J.; Kim, S. Downregulation of lamin A by tumor suppressor AIMP3/p18 leads to a progeroid phenotype in mice. Aging Cell 2010, 9, 810-822. [CrossRef] [PubMed]

93. Xie, W.; Burke, B. Nuclear networking. Nucleus 2017, 8, 323-330. [CrossRef] [PubMed]

94. Bond, M.R.; Hanover, J.A. A little sugar goes a long way: The cell biology of O-GlcNAc. J. Cell Biol. 2015, 208, 869-880. [CrossRef] [PubMed]

95. Ma, J.; Hart, G.W. Protein O-GlcNAcylation in diabetes and diabetic complications. Expert Rev. Proteom. 2013, 10, 365-380. [CrossRef] [PubMed]

96. Bronshtein, I.; Kepten, E.; Kanter, I.; Berezin, S.; Lindner, M.; Redwood, A.B.; Mai, S.; Gonzalo, S.; Foisner, R.; Shav-Tal, Y.; et al. Loss of lamin A function increases chromatin dynamics in the nuclear interior. Nat. Commun. 2015, 6, 8044. [CrossRef] [PubMed]

97. Cesarini, E.; Mozzetta, C.; Marullo, F.; Gregoretti, F.; Gargiulo, A.; Columbaro, M.; Cortesi, A.; Antonelli, L.; Di Pelino, S.; Squarzoni, S.; et al. Lamin A/C sustains PcG protein architecture, maintaining transcriptional repression at target genes. J. Cell Biol. 2015, 211, 533-551. [CrossRef] [PubMed]

98. Ronningen, T.; Shah, A.; Oldenburg, A.R.; Vekterud, K.; Delbarre, E.; Moskaug, J.O.; Collas, P. Prepatterning of differentiation-driven nuclear lamin A/C-associated chromatin domains by GlcNAcylated histone H2B. Genome Res. 2015, 25, 1825-1835. [CrossRef] [PubMed]

99. Perovanovic, J.; Dell'Orso, S.; Gnochi, V.F.; Jaiswal, J.K.; Sartorelli, V.; Vigouroux, C.; Mamchaoui, K.; Mouly, V.; Bonne, G.; Hoffman, E.P. Laminopathies disrupt epigenomic developmental programs and cell fate. Sci. Transl. Med. 2016, 8, 335ra358. [CrossRef] [PubMed]

(C) 2018 by the authors. Licensee MDPI, Basel, Switzerland. This article is an open access article distributed under the terms and conditions of the Creative Commons Attribution (CC BY) license (http:/ / creativecommons.org/licenses/by/4.0/). 